Research Article

\title{
Prevention of Oxygen-Induced Inflammatory Lung Injury by Caffeine in Neonatal Rats
}

\author{
Stefanie Endesfelder $\mathbb{I D}^{1}{ }^{1}$ Evelyn Strauß, ${ }^{1}$ Ivo Bendix $\left(\mathbb{D},{ }^{2}\right.$ Thomas Schmitz ${ }^{\mathbb{D}}{ }^{1}$ \\ and Christoph Bührer $\mathbb{1}^{1}$ \\ ${ }^{1}$ Department of Neonatology, Charité-Universitätsmedizin Berlin, Berlin, Germany \\ ${ }^{2}$ Department of Pediatrics I, Neonatology and Experimental Perinatal Neurosciences, University Hospital Essen, University Duisburg- \\ Essen, Essen, Germany
}

Correspondence should be addressed to Stefanie Endesfelder; stefanie.endesfelder@charite.de

Received 11 May 2020; Revised 15 July 2020; Accepted 18 July 2020; Published 8 August 2020

Academic Editor: Christopher Horst Lillig

Copyright (c) 2020 Stefanie Endesfelder et al. This is an open access article distributed under the Creative Commons Attribution License, which permits unrestricted use, distribution, and reproduction in any medium, provided the original work is properly cited.

Background. Preterm birth implies an array of respiratory diseases including apnea of prematurity and bronchopulmonary dysplasia (BPD). Caffeine has been introduced to treat apneas but also appears to reduce rates of BPD. Oxygen is essential when treating preterm infants with respiratory problems but high oxygen exposure aggravates BPD. This experimental study is aimed at investigating the action of caffeine on inflammatory response and cell death in pulmonary tissue in a hyperoxia-based model of BPD in the newborn rat. Material/Methods. Lung injury was induced by hyperoxic exposure with $80 \%$ oxygen for three (P3) or five (P5) postnatal days with or without recovery in ambient air until postnatal day 15 (P15). Newborn Wistar rats were treated with PBS or caffeine $(10 \mathrm{mg} / \mathrm{kg})$ every two days beginning at the day of birth. The effects of caffeine on hyperoxicinduced pulmonary inflammatory response were examined at P3 and P5 immediately after oxygen exposure or after recovery in ambient air (P15) by immunohistological staining and analysis of lung homogenates by ELISA and qPCR. Results. Treatment with caffeine significantly attenuated changes in hyperoxia-induced cell death and apoptosis-associated factors. There was a significant decrease in proinflammatory mediators and redox-sensitive transcription factor $\mathrm{NF} \kappa \mathrm{B}$ in the hyperoxia-exposed lung tissue of the caffeine-treated group compared to the nontreated group. Moreover, treatment with caffeine under hyperoxia modulated the transcription of the adenosine receptor (Adora)1. Caffeine induced pulmonary chemokine and cytokine transcription followed by immune cell infiltration of alveolar macrophages as well as increased adenosine receptor (Adora1, 2a, and $2 \mathrm{~b}$ ) expression. Conclusions. The present study investigating the impact of caffeine on the inflammatory response, pulmonary cell degeneration and modulation of adenosine receptor expression, provides further evidence that caffeine acts as an antioxidative and anti-inflammatory drug for experimental oxygen-mediated lung injury. Experimental studies may broaden the understanding of therapeutic use of caffeine in modulating detrimental mechanisms involved in BPD development.

\section{Introduction}

Through intensive medical care, the survival rate of extremely and very small premature infants has improved, whereas the incidence of developmental deficits and the risk of chronic diseases is almost unchanged [1]. Prematurely born children are already exposed to higher oxidative stress at birth [2], and due to the fundamental immaturity of the organs and organ systems, as well as their immature antioxidant defense [3], they are also unable to adapt to it ade- quately. An additive oxygen therapy for the treatment of respiratory instabilities can increase this effect [4]. Currently, long-term observations of premature infants are increasingly indicating that chronically increased oxidative stress levels could be the cause of chronic diseases in adulthood, e.g., metabolic syndrome, diabetes, and respiratory diseases in consequence of bronchopulmonary dysplasia (BPD) [5-7]. Oxidative stress in correlation with the immature developmental stage of the lungs and the influence of exogenous factors, such as mechanical stress and post- or antenatal 
infections, are among the most important reasons for the complex and multifactorial mechanisms of BPD [8-10]. $\mathrm{BPD}$ is associated with a higher risk of short- and longterm respiratory diseases and morbidity, accompanied by impaired lung structure and function. To date, no effective or preventive therapy of BPD is available.

Well-tolerated therapeutic strategies exist to alleviate premature lung injury such as corticosteroids $[11,12]$, surfactant [13], noninvasive respiratory assistance and lung protective ventilation procedures [14], careful oxygen usage [15], and antioxidants [16]. Most therapeutic approaches exhibit no effects in the symptomatic treatment or prevention of BPD, with the exception of the antioxidants vitamin A and caffeine, although efficacy is not fully established. A small but beneficial effect of vitamin A in lowering rates of BPD has been found in preterm neonates born before 29 weeks' gestation $[17,18]$. Data from initial clinical studies of caffeine therapy show a reduction in BPD rates $[19,20]$ and significant improvement of lung function [21]. The discussed early prophylactic caffeine treatment before extubation is partly associated with a reduced incidence of BPD [22-24] but also linked with a higher mortality compared to a later start of caffeine administration ( $>3$ postnatal days) $[25,26]$.

The molecular mechanisms of BPD are complex. Baroand volutrauma and oxygen toxicity are thought to be the main triggers [8]. Morphological changes due to oxidative stress result in the disruption of lung development [27], accompanied by increased proinflammatory cytokine and chemokine expression and immune cell infiltration in lung tissue [28-30]. Apoptosis and proliferation play an important role in normal cell turnover and tissue development. Mechanical ventilation and elevated oxygen concentration increase the numbers of apoptotic cells in human foetal lungs $[31,32]$.

Hyperoxia-based BPD models [8, 33] are essential for better understanding and treating long-term pulmonary sequelae, and similar histological changes occur in hyperoxia-exposed rodent pups and human preterm infants [34-36]. Newborn postnatal rats correlate in terms of developmental stages at birth with the saccular phase (E18-P4; human 24-38 weeks of gestation age) and then with the first/classical phase of alveolarization (P4-P21; human 36 weeks of gestation age to postnatal age), which overlaps with the second/continuous phase of alveolarization (P14-P60) [37].

Oxygen toxicity is mediated by the production and accumulation of excessive reactive oxygen species (ROS), causes oxidative stress [38], and depleted antioxidant levels [39]. Supraphysiologic oxygen can cause oxygen toxicity and inflammation, ultimately leading to hyperoxic lung injury and impairment of lung development caused of an influx of inflammatory cells, increased pulmonary permeability, simplification of lung structure, and cell death [9, 40]. Damage to the developing lung may be caused directly by the generation of ROS as cell toxin or indirectly through the activation of inflammatory responses $[41,42]$. The inflammatory reaction is triggered by hyperoxia in turn worsens the oxidative toxicity [43]. It has not yet been conclusively determined whether under oxidative stress caffeine acts as an antagonist to adenosine receptors [44] or through antioxidant proper- ties [39], anti-inflammatory effects $[45,46]$, and/or the reduction of endoplasmic reticulum stress [47].

Therefore, this study is aimed at investigating the action of caffeine on main mediators of inflammatory response and cell death in pulmonary tissue in a hyperoxia-based model of BPD in the newborn rat.

\section{Materials and Methods}

2.1. Ethics Statement. Time-pregnant Wistar rat dams were obtained from the Department of Experimental Medicine (FEM, Charité-Universitätsmedizin Berlin, Germany). The adult rats were housed in individual cages under environment-controlled conditions with a constant $12 \mathrm{~h} / 12 \mathrm{~h}$ light/dark cycle, ambient temperature, and relative humidity of 40-60\% with ad libitum access to the same food and water. All animal experimental procedures were approved by the local animal welfare authorities (LAGeSo, approval number G-0088/16) and followed institutional guidelines as well as ARRIVE guidelines.

2.2. Oxygen Exposure and Drug Administration. As previously described [39], pups from different litters and both sexes were pooled and randomized within $12 \mathrm{~h}$ of birth and returned to the dams. Sample size calculation was performed in $\mathrm{G} *$ Power V3.1.2 [48]. The newborn rats were randomly assigned to room air (normoxia, NO) or oxygen-enriched atmosphere (hyperoxia, HY) treatment. The pups in hyperoxia subgroups were reared with the dams in an atmosphere containing $80 \%$ oxygen (OxyCycler BioSpherix, Lacona, NY) from postnatal day (P)0 to P3 $(n=7-8)$ or P0 to P5 $(n=6-8)$; in parallel, the pups in normoxia groups were reared with the dams under room air conditions. To avoid oxygen toxicity in the nursing mothers, they were rotated between the hyperoxic and normoxic litters every $24 \mathrm{~h}$. The rats were divided into four groups, each for the same exposure times to (i) normoxia (NO, control group): $21 \%$ oxygen application of vehicle (phosphate-buffered saline (PBS)); (ii) normoxia with caffeine (NOC): $21 \%$ oxygen with caffeine $(10 \mathrm{mg} / \mathrm{kg}$, Sigma, Steinheim, Germany); (iii) hyperoxia (HY): $80 \%$ oxygen with vehicle (PBS); and (iv) hyperoxia with caffeine (HYC): $80 \%$ oxygen with caffeine $(10 \mathrm{mg} / \mathrm{kg}) .10 \mathrm{mg} / \mathrm{kg}$ of pure caffeine is equivalent to $20 \mathrm{mg} / \mathrm{kg}$ caffeine citrate, which is used clinically. Rat pups received either drug or vehicle injection intraperitoneally (i.p.) as a fixed proportion of their body weight ( $100 \mu \mathrm{l} / 10 \mathrm{~g})$ every $48 \mathrm{~h}$ beginning on the day of birth (P0). Caffeine or vehicle was administered to the pups with a total of three postnatal days of oxygen exposure (P0-P3) on the day of birth (P0) and on $\mathrm{P} 2$ and for the rat pups with a total of five days of postnatal oxygen exposure (P0-P5) on the day of birth (P0) and on $\mathrm{P} 2$ and $\mathrm{P} 4$. The rat pups were examined after the oxygen exposure (P3, P5) either directly or after recovery in room air at P15 (P3_P15, P5_P15). No pups died during hyperoxia. Caffeine plasma concentrations and weight profiles were determined and presented in the previous work [39].

2.3. Tissue Preparation. At the experimental endpoints (P3; P3_P15; P5; P5_P15), rat pups were anaesthetized with an 
i.p. injection of ketamine (100 mg/kg), xylazine $(20 \mathrm{mg} / \mathrm{kg})$, and acepromazine $(3 \mathrm{mg} / \mathrm{kg})$ and then transcardially perfused, as previously described [39]. The heart lung block was immediately removed, and the lungs were snap-frozen in liquid nitrogen and stored at $-80^{\circ} \mathrm{C}$. The perfusion was carried out with $\mathrm{PBS}$ ( $\mathrm{pH} 7.4$ ) for the molecular analysis and for immunohistochemical analysis followed by perfusion with $4 \%$ paraformaldehyde ( $\mathrm{pH} \mathrm{7.4)}$; the lungs were postfixed at $4^{\circ} \mathrm{C}$ for 1 day, embedded in paraffin, and processed for histological staining.

2.4. RNA Extraction and Quantitative Real-Time PCR. Pulmonary tissue procurement has already been described [39]. Briefly, total RNA was isolated from snap-frozen tissue by acidic phenol/chloroform extraction (peqGOLD RNAPure $^{\mathrm{TM}}$; PEQLAB Biotechnologie, Erlangen, Germany), and $2 \mu \mathrm{g}$ of RNA was DNase treated and reverse-transcribed. The PCR products of adenosine A1 receptor (Adora1), adenosine $\mathrm{A} 2 \mathrm{a}$ receptor (Adora2a), adenosine $\mathrm{A} 2 \mathrm{~b}$ receptor (Adora2b), apoptosis inducing factor, mitochondria associated (AIF), caspase 3 (Casp3), CD74 molecule (CD74), C$\mathrm{X}-\mathrm{C}$ motif chemokine ligand 1 (CINC-1), glutamatecysteine ligase catalytic subunit (GCLC), hypoxanthine phosphoribosyltransferase 1 (HPRT), interferon gamma (IFN $\gamma)$, interleukin 1 alpha (IL-1 $\alpha$ ), interleukin 1 beta (IL-1 $\beta$ ), interleukin 10 (IL-10), C-C motif chemokine ligand 2 (MCP-1), Macrophage migration inhibitory factor (MIF), C-X-C motif chemokine ligand 2 (MIP-2), nuclear factor kappa B subunit $1(\mathrm{NF} \kappa \mathrm{B} 1)$, nuclear factor kappa B subunit $2(\mathrm{NF} \kappa \mathrm{B} 2)$, and tumor necrosis factor (TNF $\alpha)$ were quantified in real time with the sequences summarized in Table 1. PCR and detection were performed with qPCR BIO Mix Hi-ROX (NIPPON Genetics Europe, Düren, Germany) with HPRT used as an internal reference. The expression of target genes was analyzed with the StepOnePlus real-time PCR system (Applied Biosystems, Carlsbad, CA, USA) according to the $2^{-\Delta \Delta C T}$ method [49].

2.5. Protein Extraction. The snap-frozen lung tissue was chopped in a radioimmunoprecipitation assay buffer (RIPA; Thermo Fisher Scientific, Waltham, MA, USA), centrifuged at $3000 \times g$ for $10 \mathrm{~min}$ at $4^{\circ} \mathrm{C}$, and the supernatant of homogenized lung tissue was obtained. Protein concentrations were determined using the Pierce BCA kit (Pierce/Thermo Fisher Scientific, Rockford, IL, USA) as described in [50].

2.6. Enzyme-Linked Immunosorbent Assay (ELISA). Tumor necrosis factor $\alpha$ (TNF $\alpha$ ) concentration was analyzed in samples of lung homogenate using rat TNF $\alpha / T N F S F 1 A$ Quantikine ELISA Kit (R\&D Systems GmbH, WiesbadenNordenstadt, Germany) according to the manufacturer's instructions and as described in [51]. TNF $\alpha$ concentration was estimated from the standard curve and expressed as picogram per milligram protein.

2.7. Immunohistochemistry. Paraffin-embedded lung sections were deparaffinized in Roti-Histol (Carl Roth, Karlsruhe, Germany), rehydrated in ethanol, and subjected to immunostaining. Antigen retrieval was done in a heated citrate buffer at pH 6.0 for $20 \mathrm{~min}$. To block unspecific proteins, slices were
TABLE 1: Sequences of oligonucleotides.

\begin{tabular}{|c|c|c|}
\hline & Oligonucleotide sequence $5^{\prime}-3^{\prime}$ & Accession no. \\
\hline \multicolumn{3}{|l|}{ Adoral } \\
\hline Forward & GGATCGATACCTCCGAGTCAAG & NM_017155.2 \\
\hline Reverse & AATCCAGCAGCCAGCTATGG & \\
\hline Probe & TCTCCGGTACAAGACAGT & \\
\hline \multicolumn{3}{|l|}{ Adora $2 a$} \\
\hline Forward & GGGAGCCAGAGCAAGAGGTA & NM_053294.3 \\
\hline Reverse & CTGCATCTCССААAATCATGAC & \\
\hline Probe & AGAACCCTGAAGCCGAGA & \\
\hline \multicolumn{3}{|l|}{ Adora $2 b$} \\
\hline Forward & TCGTGCTGGTGCTCACACA & NM_017161.1 \\
\hline Reverse & TCGTGTTCCAGTGACCAAACC & \\
\hline Probe & ATCTTTAGCCTCTTGGCGGT & \\
\hline \multicolumn{3}{|l|}{$A I F$} \\
\hline Forward & $\begin{array}{c}\text { CACAAAGACACTGCAGTTCAG } \\
\text { ACA }\end{array}$ & NM_031356.1 \\
\hline Reverse & $\begin{array}{c}\text { AGGTCCTGAGCAGAGACATAG } \\
\text { AAAG }\end{array}$ & \\
\hline Probe & AGAAGCATCTATTTCCAGCC & \\
\hline \multicolumn{3}{|l|}{ Casp3 } \\
\hline Forward & $\begin{array}{c}\text { ACAGTGGAACTGACGATGATA } \\
\text { TGG }\end{array}$ & NM_012922.2 \\
\hline Reverse & AATAGTAACCGGGTGCGGTAGA & \\
\hline Probe & ATGCCAGAAGATACCAGTGG & \\
\hline \multicolumn{3}{|l|}{ CD74 } \\
\hline Forward & CCCGTGAAGAATGTTACCAA & NM_013069.2 \\
\hline Reverse & AACAGCCACTGTTTCATCCA & \\
\hline Probe & ATGAATGGTCTGGACTGGAA & \\
\hline \multicolumn{3}{|l|}{ CINC-1 } \\
\hline Forward & GCTGTCAGTGCCTGCAGACA & NM_030845.1 \\
\hline Reverse & $\begin{array}{c}\text { GACCATTCTTGAGTGTGGCTA } \\
\text { TGA }\end{array}$ & \\
\hline Probe & CACTTCAAGAACATCCAGAG & \\
\hline \multicolumn{3}{|l|}{ GCLC } \\
\hline Forward & GGAGGACAACATGAGGAAACG & NM_012815.2 \\
\hline Reverse & GCTCTGGCAGTGTGAATCCA & \\
\hline Probe & TCAGGCTCTTTGCACGATAA & \\
\hline \multicolumn{3}{|l|}{$H P R T$} \\
\hline Forward & $\begin{array}{c}\text { GGAAAGAACGTCTTGATTGTT } \\
\text { GAA }\end{array}$ & NM_012583.2 \\
\hline Reverse & CCAACACTTCGAGAGGTCCTTTT & \\
\hline Probe & $\begin{array}{c}\text { CTTTCCTTGGTCAAGCAGTAC } \\
\text { AGCCCC }\end{array}$ & \\
\hline \multicolumn{3}{|l|}{$I F N \gamma$} \\
\hline Forward & CGGACCAGAGACCCTTTGC & $\frac{\mathrm{NM}_{-}}{001082479.1}$ \\
\hline Reverse & GCCTGTGGGCTTGTTGAAGT & \\
\hline Probe & CTCTTCAGTTCGTGTGTGG & \\
\hline \multicolumn{3}{|l|}{$I L-1 \alpha$} \\
\hline Forward & GAAGATGACCTGGAGGCCATAG & NM_017019.1 \\
\hline Reverse & TCCTGCTTGACGATCCTTATCA & \\
\hline
\end{tabular}


TABLe 1: Continued.

\begin{tabular}{|c|c|c|}
\hline & Oligonucleotide sequence $5^{\prime}-3^{\prime}$ & Accession no. \\
\hline Probe & AAGAGACCATCCAACCCAGA & \\
\hline \multicolumn{3}{|l|}{$I L-1 \beta$} \\
\hline Forward & СТССАССТСAATGGACAGAACA & NM_031512.2 \\
\hline Reverse & CACAGGGATTTTGTCGTTGCT & \\
\hline Probe & CTCCATGAGCTTTGTACAAG & \\
\hline \multicolumn{3}{|l|}{$I L-10$} \\
\hline Forward & CCCTGGGAGAGAAGCTGAAGA & NM_012854.2 \\
\hline Reverse & GCTCCACTGCCTTGCTTTTATT & \\
\hline Probe & CATCGATTTCTCCCCTGTGA & \\
\hline \multicolumn{3}{|l|}{$M C P-1$} \\
\hline Forward & AGCATCCACGTGCTGTCTCA & NM_031530.1 \\
\hline Reverse & GCCGACTCATTGGGATCATC & \\
\hline Probe & AGATGCAGTTAATGCCCCAC & \\
\hline \multicolumn{3}{|l|}{$M I F$} \\
\hline Forward & GCAAGCCGGCACAGTACAT & NM_031051.1 \\
\hline Reverse & GCTCGTGCCACTAAAAGTCATG & \\
\hline Probe & CAGTGCACGTGGTCC & \\
\hline \multicolumn{3}{|l|}{$M I P-2$} \\
\hline Forward & CCTACCAAGGGTTGACTTCAAGA & NM_053647.1 \\
\hline Reverse & GCTTCAGGGTTGAGACAAACTTC & \\
\hline Probe & AGACAGAAGTCATAGCCACT & \\
\hline \multicolumn{3}{|l|}{$N F \kappa B 1$} \\
\hline Forward & GACCCAAGGACATGGTGGTT & $\begin{array}{c}\mathrm{NM}_{-} \\
001276711.1\end{array}$ \\
\hline Reverse & TCATCCGTGCTTCCAGTGTTT & \\
\hline Probe & CTGGGAATACTTCACGTGAC & \\
\hline \multicolumn{3}{|l|}{$N F \kappa B 2$} \\
\hline Forward & GCCTAAACAGCGAGGCTTCA & $\begin{array}{c}\mathrm{NM}_{-} \\
001008349.1\end{array}$ \\
\hline Reverse & TCTTCCGGCCCTTCTCACT & \\
\hline Probe & TTTCGATATGGCTGTGAAGG & \\
\hline \multicolumn{3}{|l|}{$T N F \alpha$} \\
\hline Forward & СССССААТСТGTGTССТТСТААС & NM_012675.3 \\
\hline Reverse & CGTCTCGTGTGTTTCTGAGCAT & \\
\hline Probe & TAGAAAGGGAATTGTGGCTC & \\
\hline
\end{tabular}

incubated in PBS 2\% goat serum, 1\% BSA, 0.1\% Triton X$100,0.05 \%$ Tween 20 , and $0.1 \%$ bovine gelatin. Primary antibodies were diluted in antibody diluent (Zymed Laboratories, San Francisco, CA) and incubated with the sections overnight at $4^{\circ} \mathrm{C}$. Sections were stained for anti-DNA fragmentation factor subunit beta (DFFB, $5 \mu \mathrm{m}$ section, $1: 250$, Bioss, Woburn, MA, USA), for anti-myeloperoxidase (MPO, $10 \mu \mathrm{m}$ section, $1: 200$, Thermo Fisher Scientific), and for ED1 (CD68, $10 \mu \mathrm{m}$ section, 1:200, Abcam, Cambridge, MA, USA). For detection, secondary Alexa Fluor 488conjugated goat anti-mouse IgG (Thermo Fisher Scientific) or Alexa Fluor 488-conjugated goat anti-rabbit IgG (Thermo Fisher Scientific) was applied at a dilution of $1: 200$ in antibody diluent (Zymed Laboratories) and incubated at room temperature for $1 \mathrm{~h}$. Slides were counterstained with 4,6-dia- midino-2-phenylindole (DAPI, 1:2000 in PBS, Sigma) for $10 \mathrm{~min}$ and mounted with mounting media (Shandon Immu-Mount, Thermo Fisher Scientific). Sections were analyzed blind using a Keyence compact fluorescent microscope BZ 9000 with BZ-II Viewer software and BZ-II Analyzer software (Keyence, Osaka, Japan). Green fluorescent-positive cells were counted in four (DFFB, 200x magnification) or six (MPO and ED1, 100x magnification) nonoverlapping separate fields per animal, and mean values of all images were used for statistical analysis.

2.8. Statistical Analyses. Box and Whisker plots represent the interquartile range (box) with the line representing the median, whereas whiskers show the data variability outside the upper and lower quartiles. Groups were compared using one-way analysis of variance (ANOVA) based on a partially non-Gaussian distribution with the Kruskal-Wallis test. Multiple comparisons of means were carried out using Dunn's post hoc test. A $p$ value of $<0.05$ was considered significant. All graphics and statistical analyses were performed using the GraphPad Prism 8.0 software (GraphPad Software, La Jolla, CA, USA).

\section{Results}

3.1. Caffeine Inhibits Cell Apoptosis in Pulmonary Tissue Induced by Hyperoxia. The effects of caffeine on the histopathological findings of rat pups with hyperoxia-induced lung tissue injury are shown in Figure 1 . To gain insight into the effect of caffeine on cell survival during hyperoxiainduced lung injury, apoptosis in the lung tissue was evaluated by DFFB staining. Cell apoptosis in the lung tissue was induced by hyperoxia and was detected immediately after the termination of oxygen exposure after 3 and 5 days and remained consistent even after recovery in ambient air until postnatal day 15 compared to animals exposed to room air. At all times of examination, there was a significant decrease of apoptotic cells in the caffeine-treated hyperoxia group compared to the vehicle-treated hyperoxia group (Figures 1 and $2(\mathrm{a})$ ). In accordance with the IHC results in neonatal rat lungs, the mRNA content of the effector caspase Casp3 and caspase-independent AIF increased in direct response to hyperoxia (P3 and/or P5; Figure 2(b) and (d)). The level of mRNA encoding GCLC, a rate-limiting enzyme subunit of glutathione synthesis, was upregulated in a similar way (Figure 2(c)). Hyperoxia-induced transcription of cell death-associated mediators was significantly weakened by caffeine. Caffeine under normoxia exposure had no effect of mRNA expression of the cell death associated mediators Casp3, AIF, and GCLC, compared to the control group (Figure 2(b) and (d)).

3.2. Hyperoxia-Induced Immune Cell Infiltration Is Inhibited by Caffeine. Immunohistochemistry was used to assess the infiltration of the lungs by inflammatory cells. The 3-day and 5-day hyperoxic exposure exhibited significant inflammatory cell infiltration, as compared to controls (Figures 3 and 4), and a quantitative increase of ED1-positive alveolar macrophages and MPO-positive neutrophils (Figure 5(a) 


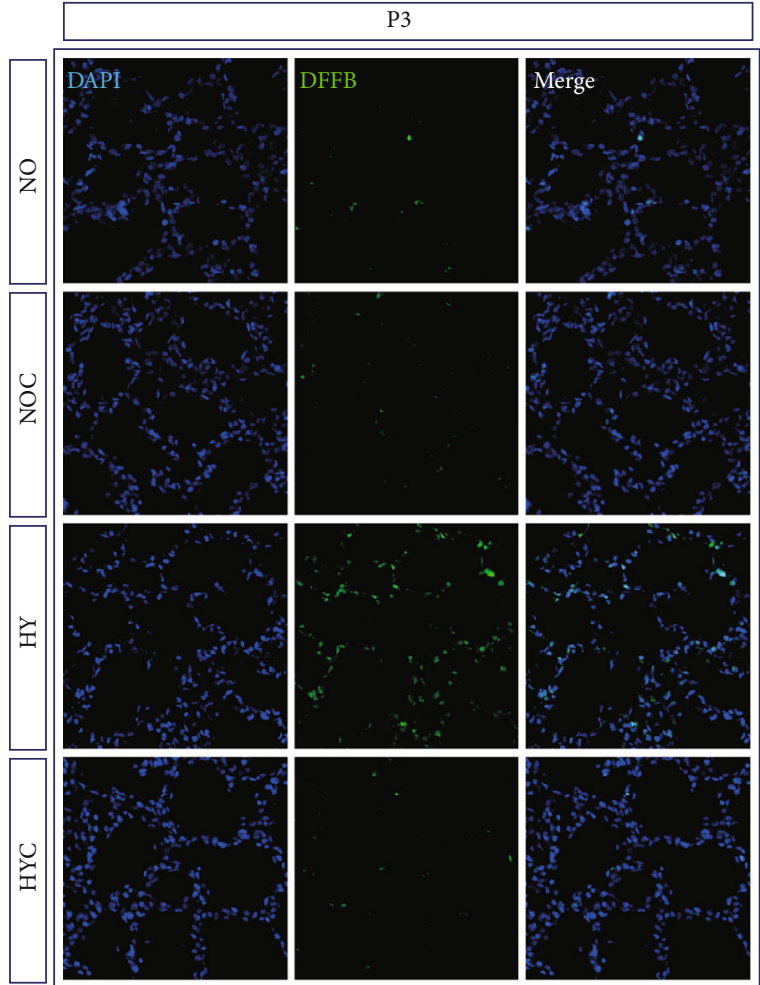

(a)

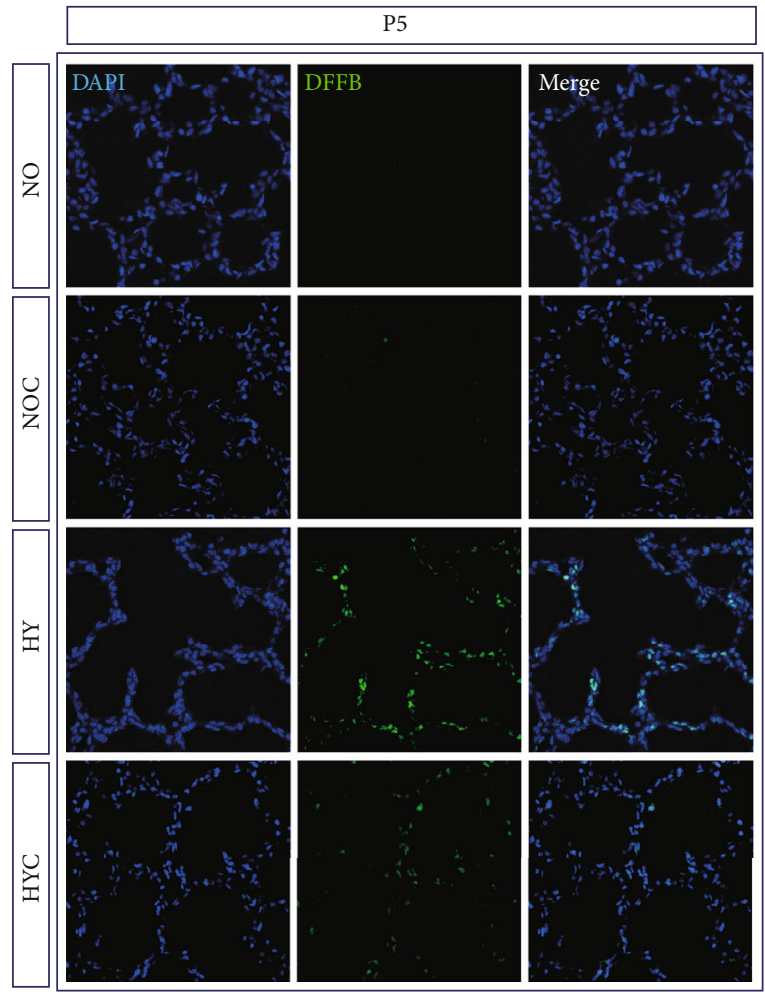

(b)

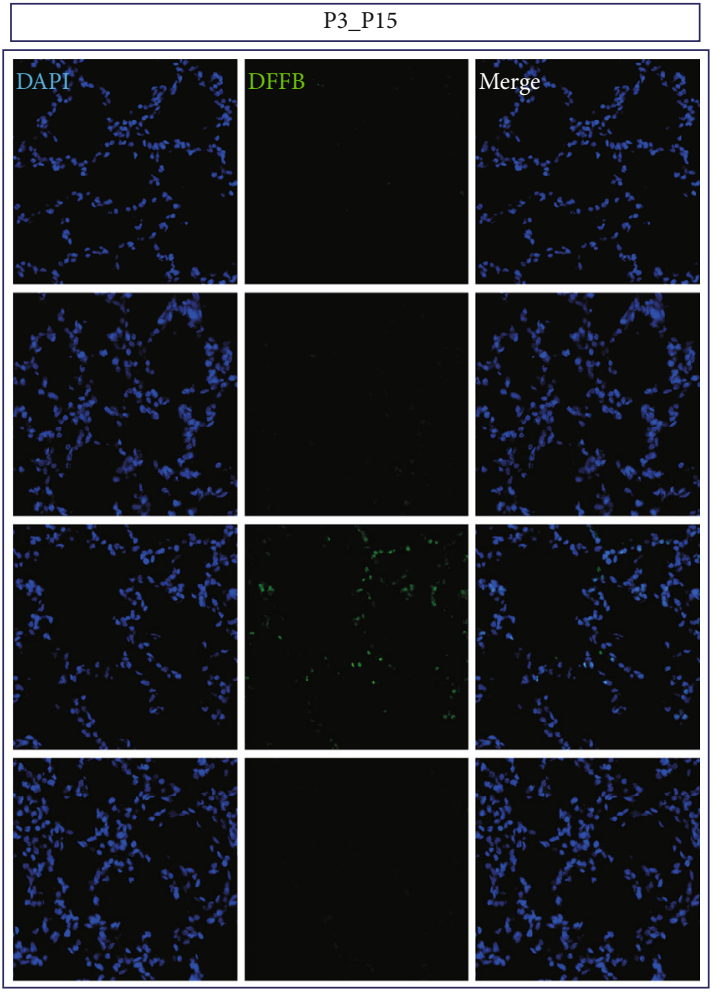

(c)

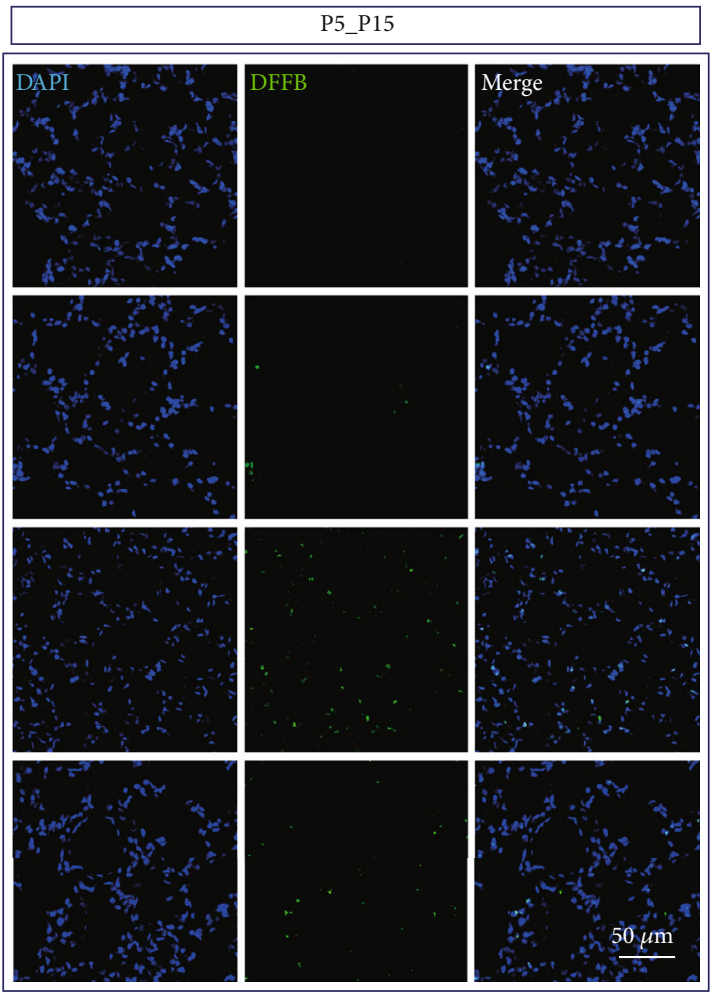

(d)

FIGURE 1: Representative photomicrographs of immunohistochemical staining of DFFB in the lungs of rat pups exposed to normoxia (NO) or hyperoxia (HY) compared to rat pups treated with caffeine (NOC, HYC). Examinations were performed at postnatal day 3 (P3 (a)) and P5 (b), or after recovery after 3-day exposure at P15 (c) or after 5-day exposure at P15 (d). Immunofluorescent images indicated DFFB (green) and nuclei (blue, DAPI). Scale bars represent $50 \mu \mathrm{m}$. 


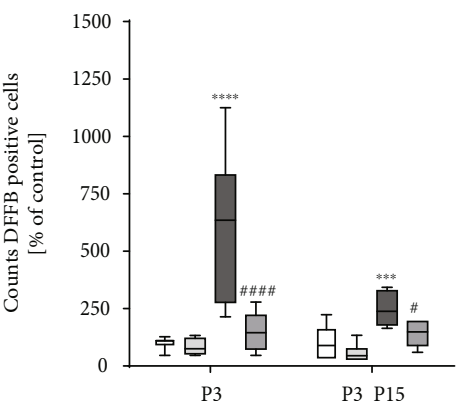

(a)

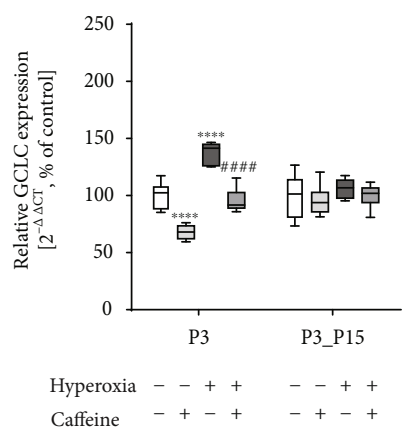

(c)
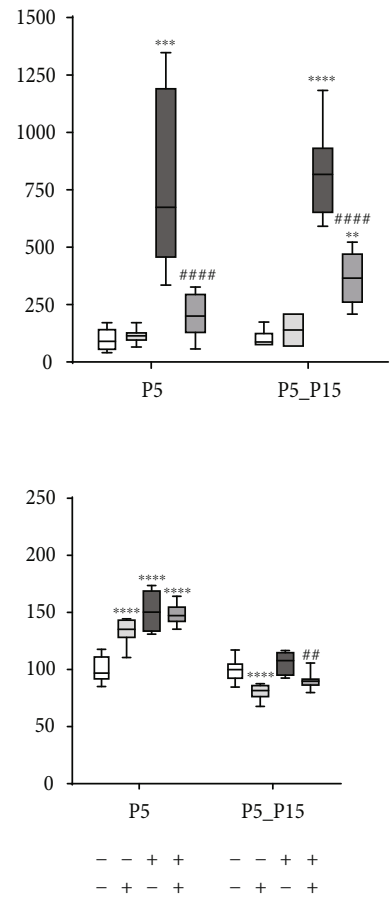

)

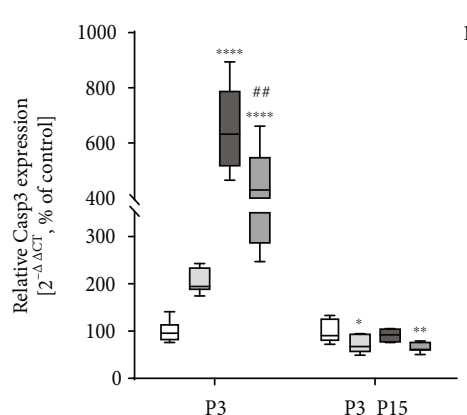

(b)

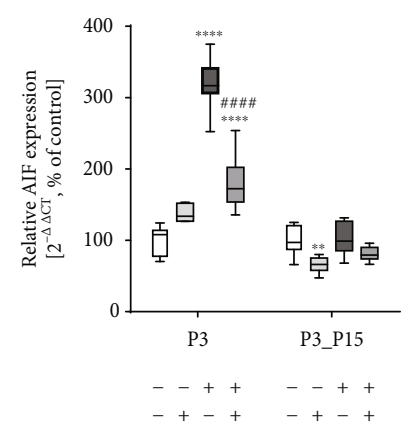

(d)
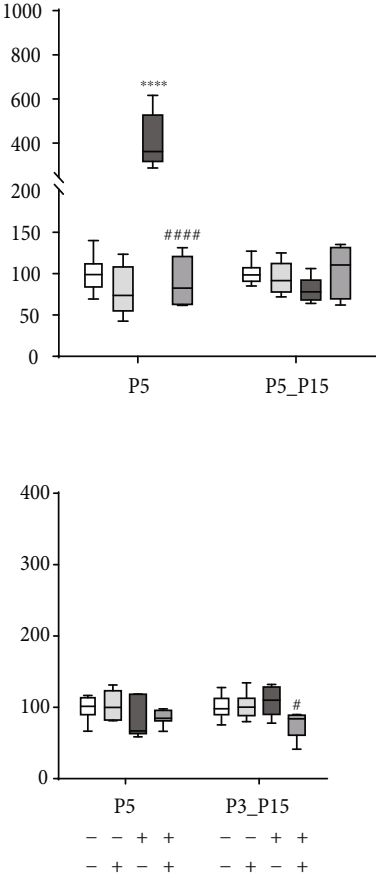

Figure 2: Quantitative analysis of (a) DFFB+ cell counts showed a marked increase in lung tissue samples of rat pups after acute oxygen exposure at P3 and P5 (deep dark grey bars) whereas caffeine treatment reduced apoptotic cells (dark grey bars). Cell death rate remained elevated even after recovery (P15). Caffeine treatment under room air (light grey bars) demonstrated no modulation of cell death. Hyperoxia within the first days of life accompanied by an increased cell death rate led to enhanced gene expression of (b) Casp3, (c) GCLC, and (d) AIF. Caffeine counteracted this. Quantification of lung homogenates was performed with qPCR for 3 days' postnatal oxygen exposure (P3) and recovery (P3_P15) and 5 days' postnatal oxygen exposure (P5) and recovery (P5_P15), respectively. Data are normalized to the level of rat pups exposed to normoxia at each time point (control $100 \%$, white bars), and the $100 \%$ values are 4.3 (P3), 1.7 (P3_P15), 3.1 (P5), and 0.7 (P5_P15) cells per $\mathrm{mm}^{2}$, respectively. $n=6$-8/group. ${ }^{*} p<0.05,{ }^{* *} p<0.01,{ }^{* * *} p<0.001$, and ${ }^{* * *} p<0.0001$

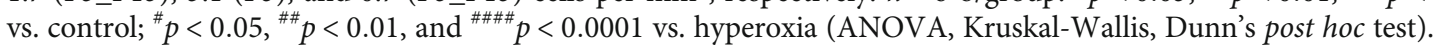

and (b)). Alveolar macrophages and neutrophils in hyperoxic lungs were still increased after recovery (Figure 5(a)). Following caffeine intervention, the number of infiltrating immune cells (i.e., ED1+ and MPO+ cells) was significantly decreased (Figures 3-5(a), (b)). Caffeine under normoxic conditions produced a significant increase in alveolar macrophages on postnatal day three (Figure 5(a)).

Chemokines play an important role in mediating immune cell recruitment in the lung during hyperoxic exposure [52]. As shown in Figure 5(c)-(e), following hyperoxia, we observed a robust increase in the expression of the cytokine-induced chemokine CINC-1, of the monocytes chemotactic chemokine MCP-1, and of the neutrophil chemotactic chemokine MIP-2 which were largely increased in the hyperoxia group compared to the normoxic group, which was ameliorated by caffeine treatment (Figure 5(c)-(e)). Notably, the increase was far more pronounced at the immature age P3 compared to the later postnatal age P5. Surprisingly, caffeine in room air-exposed rat lungs significantly increased chemokine mRNA expression at P3 (Figure 5(c)-(e)). Following hyperoxia, we detected an increase of the inflammatory mediator MIF at any time point (Figure 5(f)). Transcript levels encoding for CD74 as part of MIF receptor complex were decreased under hyperoxic exposure on postnatal day 3 (P3), and expression remained decreased even after recovery in ambient air (P3_P15, Figure 5(g)). Interestingly, CD74 mRNA was significantly elevated after five days of hyperoxia (P5) and decreased until postnatal day 15 (P5_P15; Figure 5(g)) compared to lung tissue from normoxic rat pups. Caffeine inhibited MIF transcription, which was upregulated by hyperoxia, at any time point (Figure 5(f)). In the hyperoxia-exposed lungs, caffeine decreased CD74 transcription at P3 and P5, but after recovery, it caused an increase of CD74 expression at P15 (P3/P5_P15; Figure 5(g)).

3.3. Caffeine Reduces Inflammatory Response Induced by Hyperoxia In Vivo. Given that caffeine treatment reduced cell apoptosis and immune cell infiltration in the developing lung, next, we analyzed the expression of proinflammatory cytokines in order to gain insight into the potential antiinflammatory action of caffeine. In response to hyperoxia, the concentration of TNF $\alpha$ significantly increased in lung tissue determined by ELISA at P3 only (Figure 6(a)) and was confirmed for the mRNA expression at P3 and P5 (Figure 6(b)). For both protein and mRNA, we observed an induction of $\mathrm{TNF} \alpha$ by caffeine without additional oxygen (P3 and/or P5; Figure 6(a) and (b)). In addition, hyperoxiaexposed rat pups had increased IL- $1 \alpha$, IL- $1 \beta$, and IFN $\gamma$ mRNA in lung homogenates compared to control rats at P3 


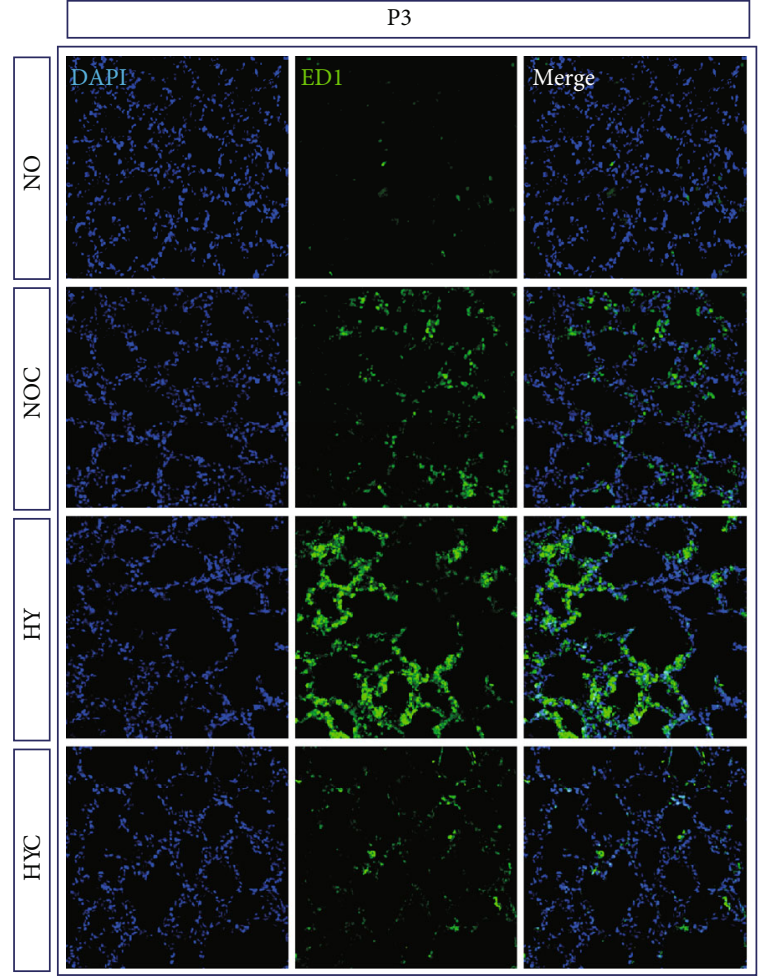

(a)

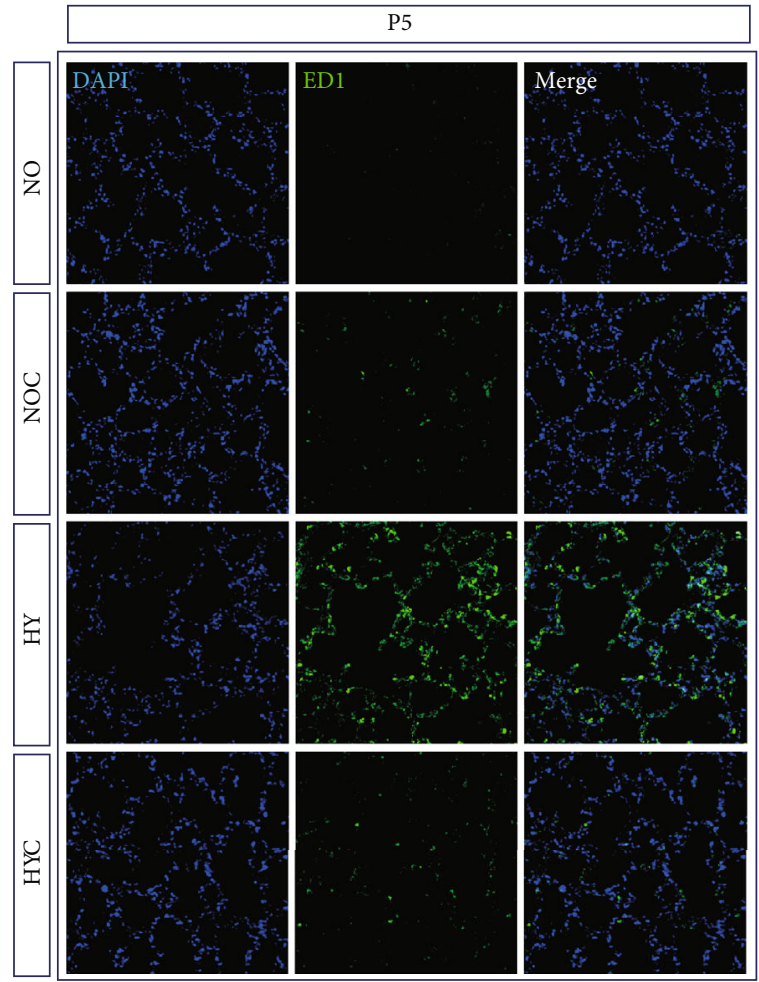

(b)

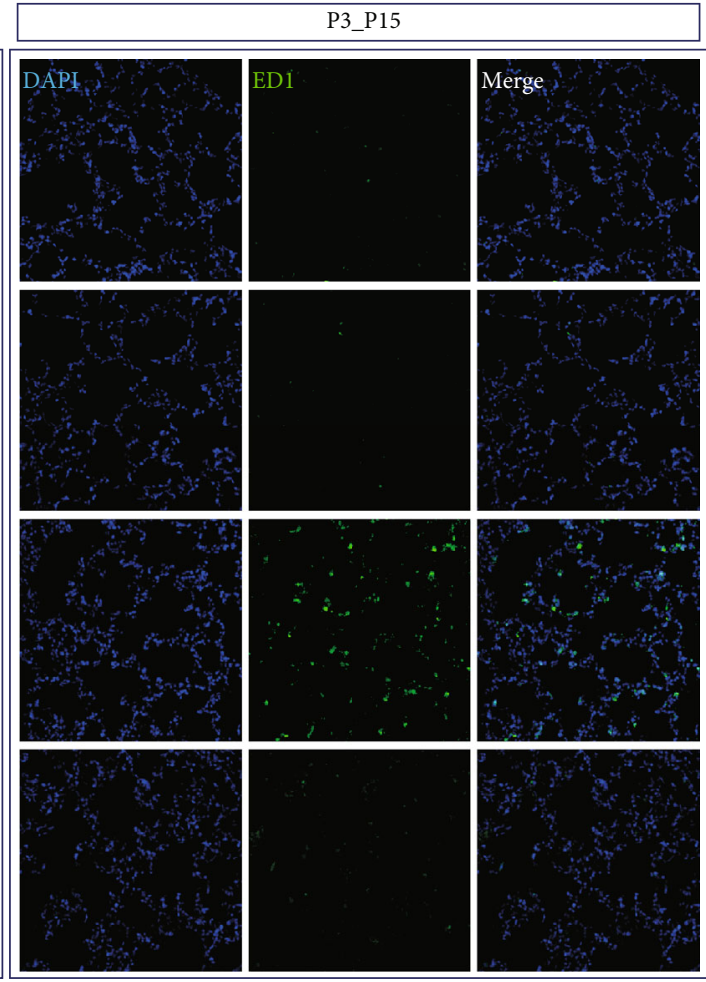

(c)

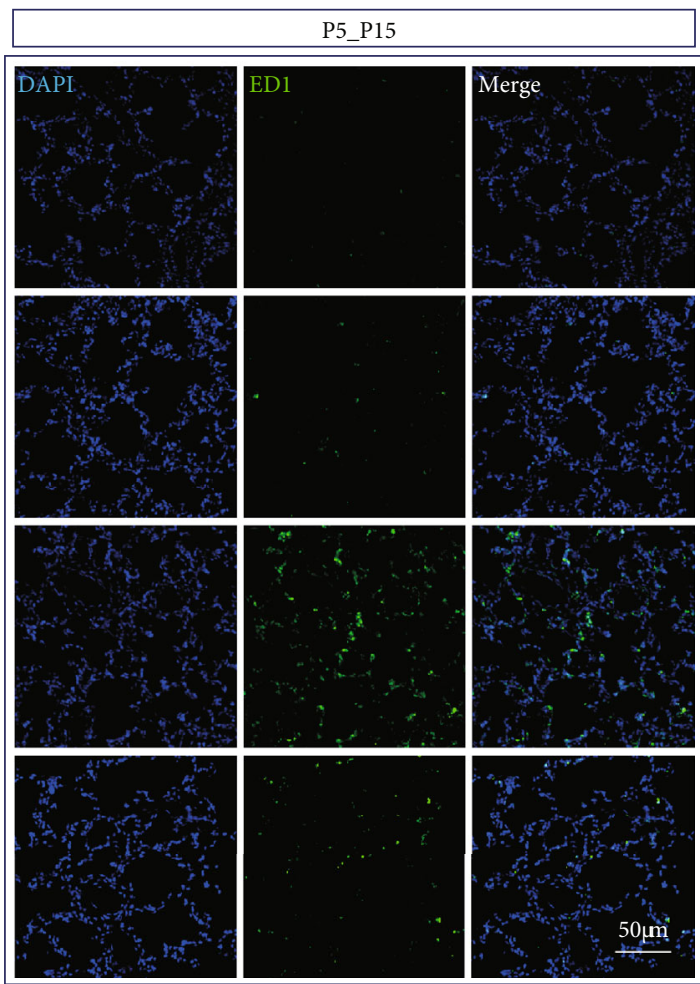

(d)

FIGURE 3: Representative micrographs of immunohistochemical staining of ED1 (CD68) in the lungs of rat pups exposed to normoxia (NO) or hyperoxia (HY) compared to rat pups treated with caffeine (NOC, HYC). Examinations were performed at postnatal day 3 (P3 (a)) and P5 (b), or after recovery after 3-day exposure at P15 (c) or after 5-day exposure at P15 (d). Immunofluorescent images indicated ED1 (green) and nuclei (blue, DAPI). Scale bars represent $100 \mu \mathrm{m}$. 


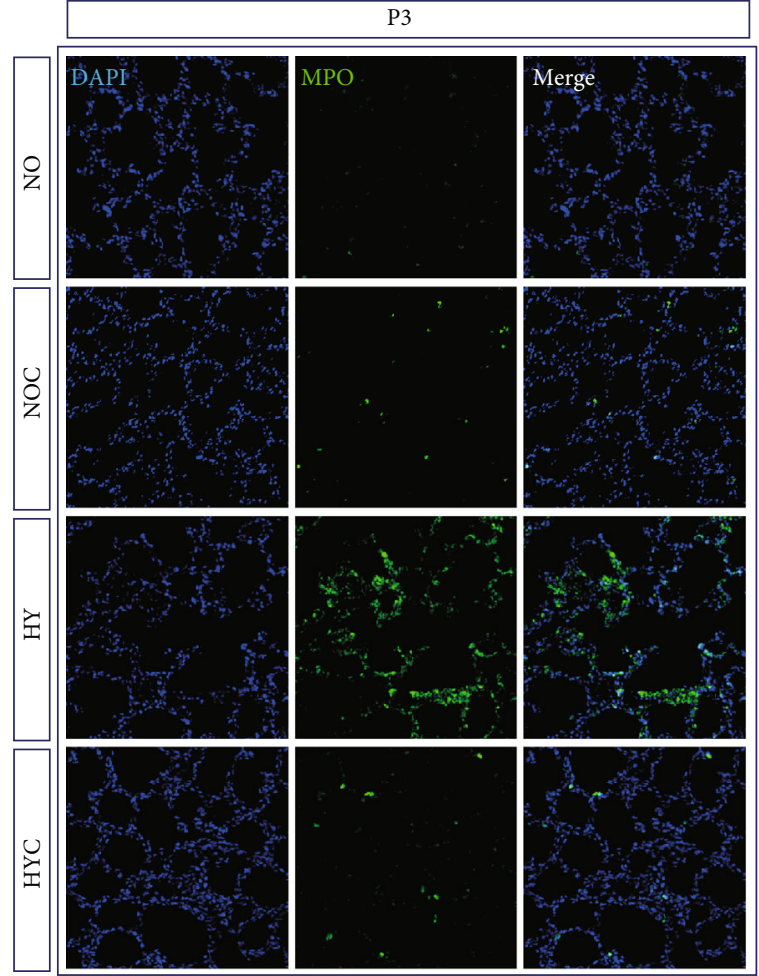

(a)

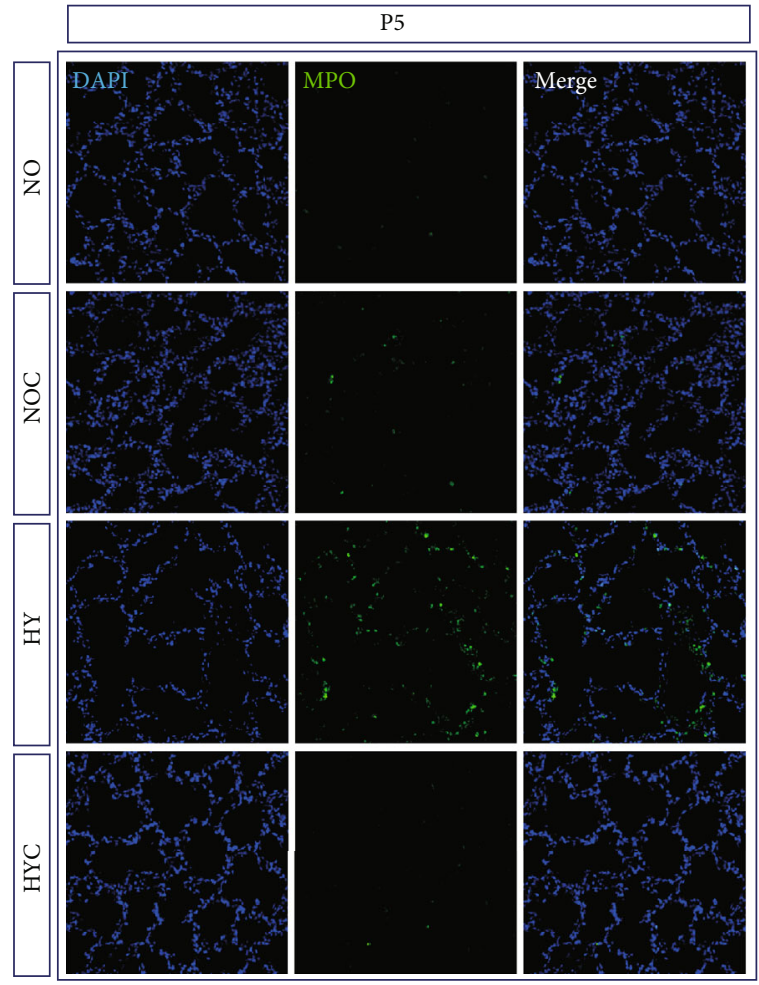

(b)

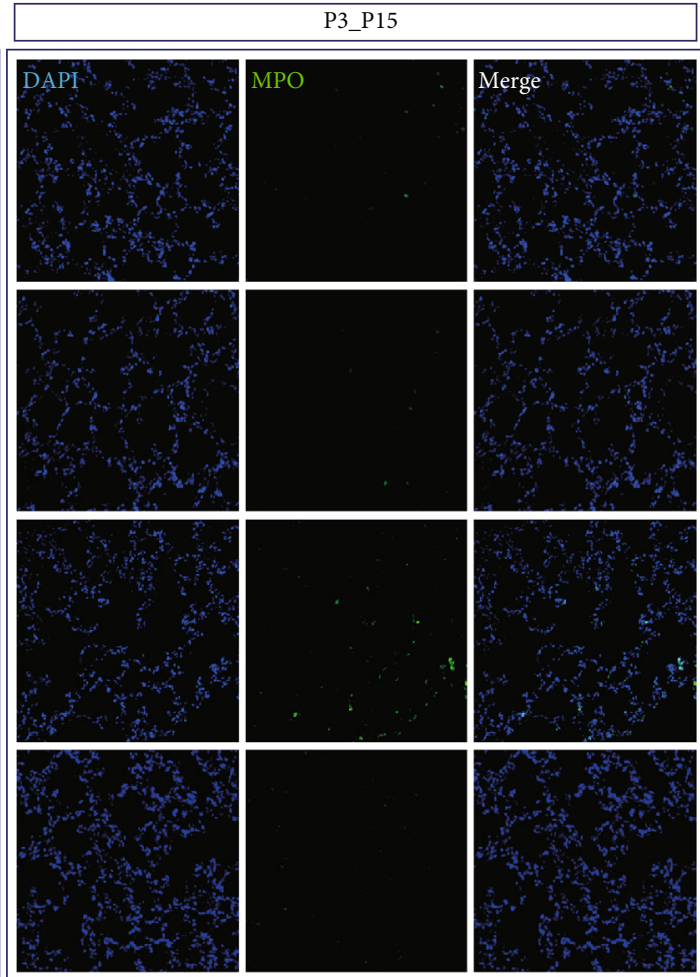

(c)

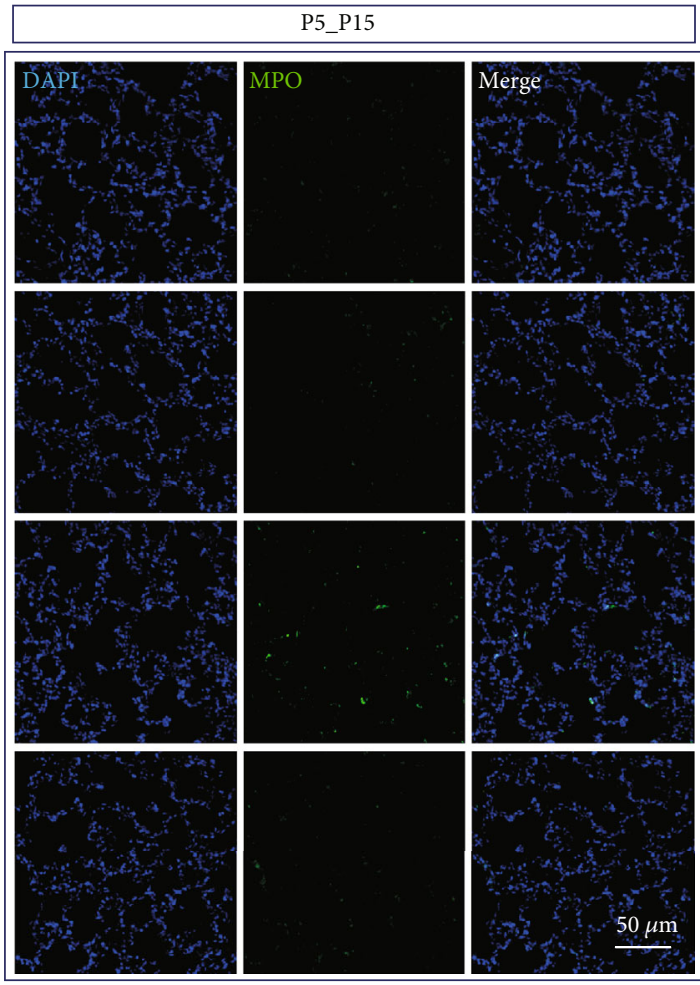

(d)

FIgURE 4: Representative micrographs of immunohistochemical staining of MPO in the lungs of rat pups exposed to normoxia (NO) or hyperoxia (HY) compared to rat pups treated with caffeine (NOC, HYC). Examinations were performed at postnatal day 3 (P3 (a)) and P5 (b), or after recovery after 3-day exposure at P15 (c) or after 5-day exposure at P15 (d). Immunofluorescent images indicated MPO (green) and nuclei (blue, DAPI). Scale bars represent $100 \mu \mathrm{m}$. 


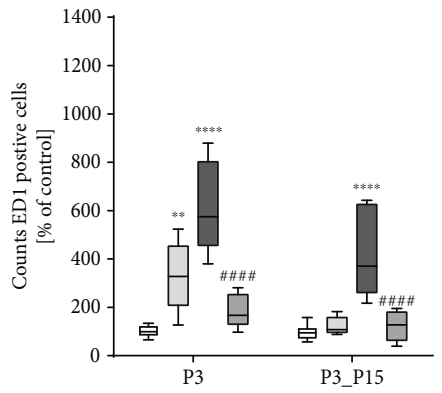

(a)

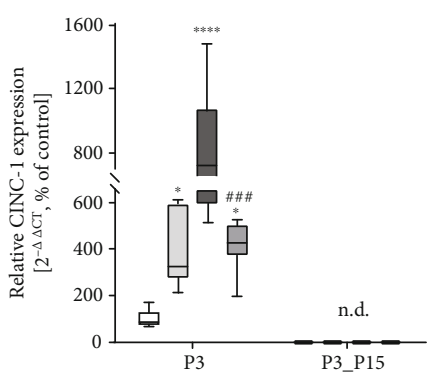

(c)

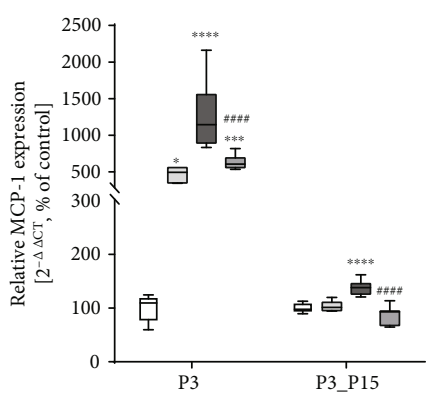

(d)

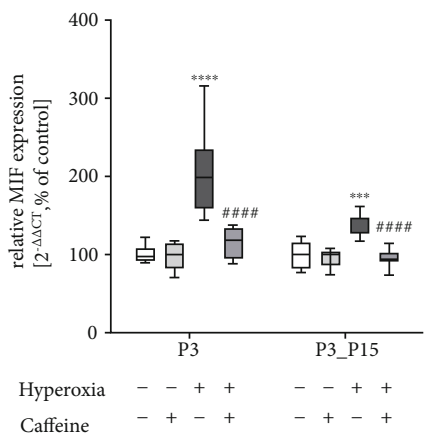

(f)
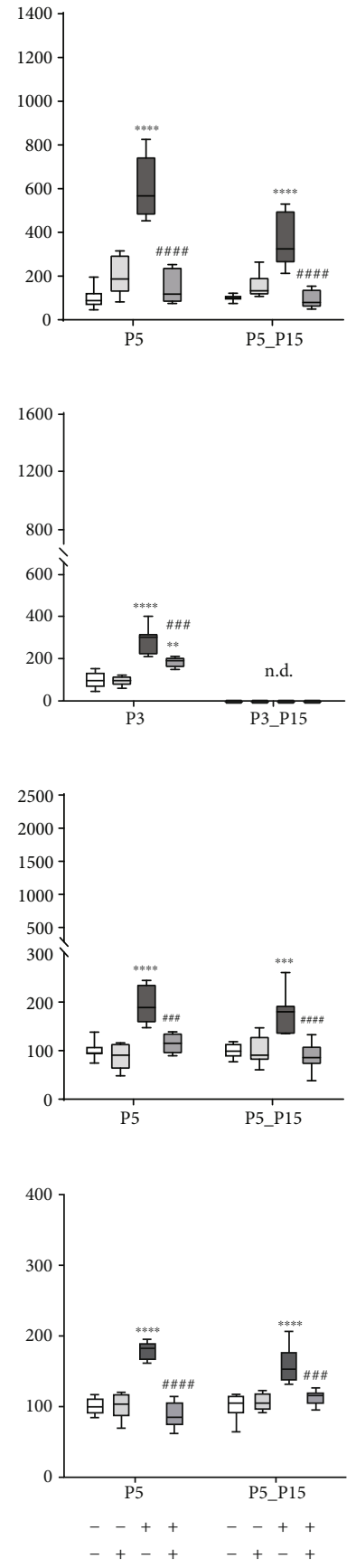
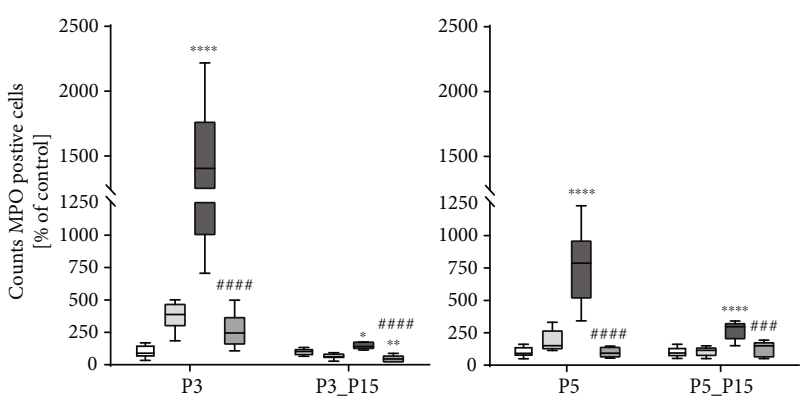

(b)
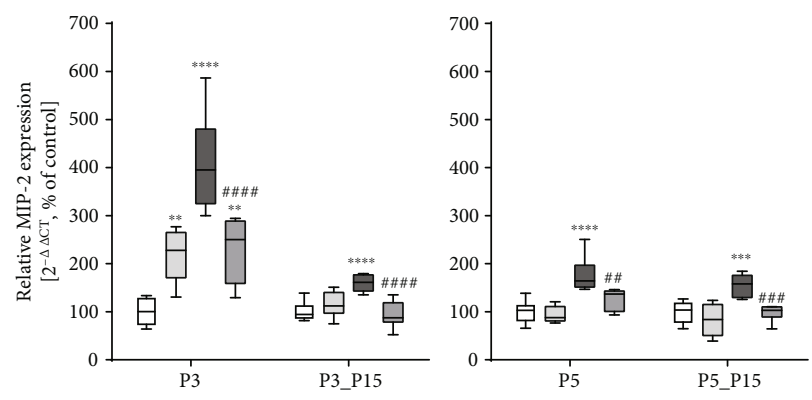

(e)
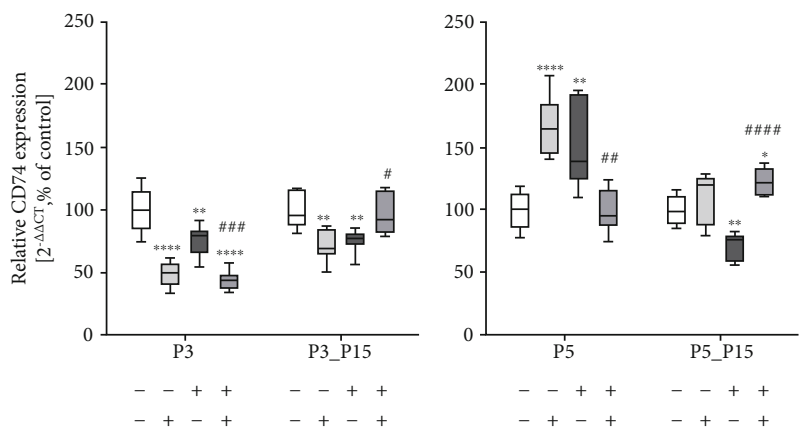

(g)

FIGURE 5: Quantitative analysis of (a) ED1+ and (b) MPO+ cell counts showed a marked accumulation in lung tissue samples of rat pups after acute oxygen exposure at P3 and P5 (deep dark grey bars) whereas caffeine treatment inhibited (a) macrophage (ED1) and (b) neutrophil (MPO) infiltration (dark grey bars). Macrophage infiltration remained elevated even after recovery (P15). Caffeine treatment under room air (light grey bars) increased counts of macrophages at P3. Hyperoxia exposure of newborn rat pups, characterized by an overwhelming immune cell influx, led to increased chemokine gene expression of (c) CINC-1, (d) MCP-1, and (e) MIP-2. Chemokine transcription is inhibited by caffeine. Caffeine under normoxic exposure increased chemokine transcription at P3. CINC-1 is not detectable (n.d.) at P15. Caffeine alleviated the hyperoxia-induced gene expression of (f) MIF, whereas hyperoxia modulated expression of the MIF receptor ( $g$ ) CD74, and caffeine counteracted this. Quantification of lung homogenates was performed with qPCR for 3 days' postnatal oxygen exposure (P3) and recovery (P3_P15) and 5 days' postnatal oxygen exposure (P5) and recovery (P5_P15), respectively. Data are normalized to the level of rat pups exposed to normoxia at each time point (control 100\%, white bars), and the $100 \%$ values for ED1/MPO are 22.4/12.7 (P3), 7.6/12.5 (P3_P15), 15.2/12.0 (P5), and 7.1/10.9 (P5_P15) cells per $\mathrm{mm}^{-2}$, respectively. $n=6-8 /$ group. ${ }^{*} p<$ $0.05,{ }^{* *} p<0.01,{ }^{* * *} p<0.001$, and ${ }^{* * * *} p<0.0001$ vs. control; ${ }^{\#} p<0.05,{ }^{\# \#} p<0.01,{ }^{\# \# \#} p<0.001$, and ${ }^{\# \# \#} p<0.0001$ vs. hyperoxia (ANOVA, Kruskal-Wallis, Dunn's post hoc test). 


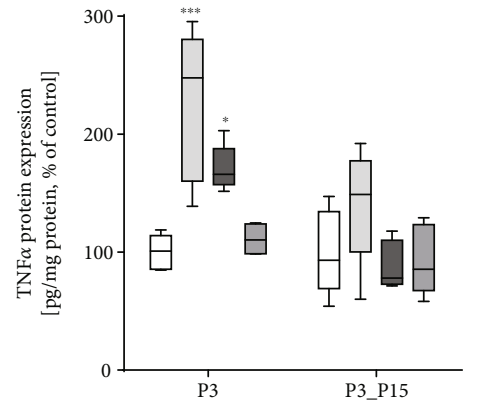

(a)

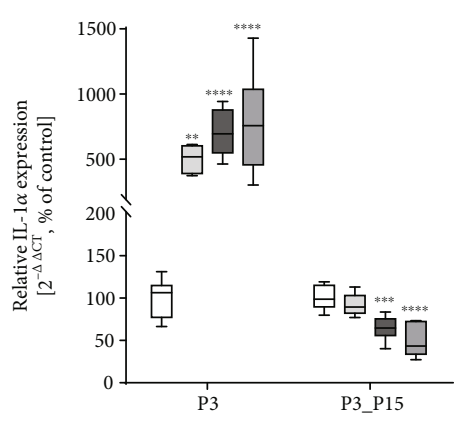

(c)

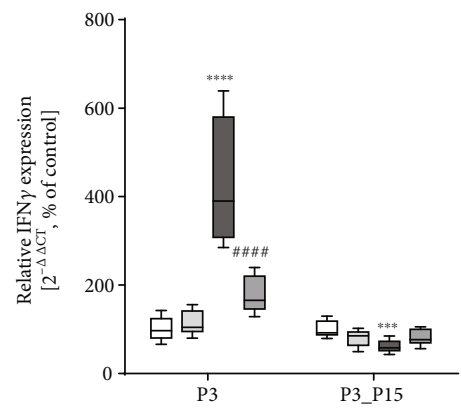

(e)
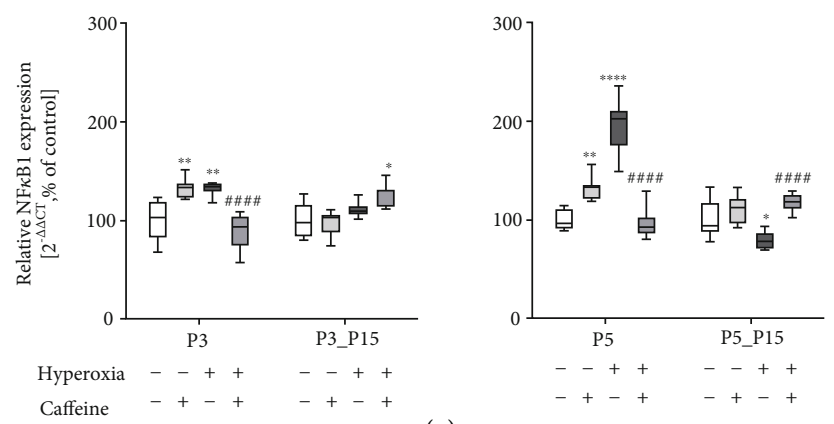

(g)
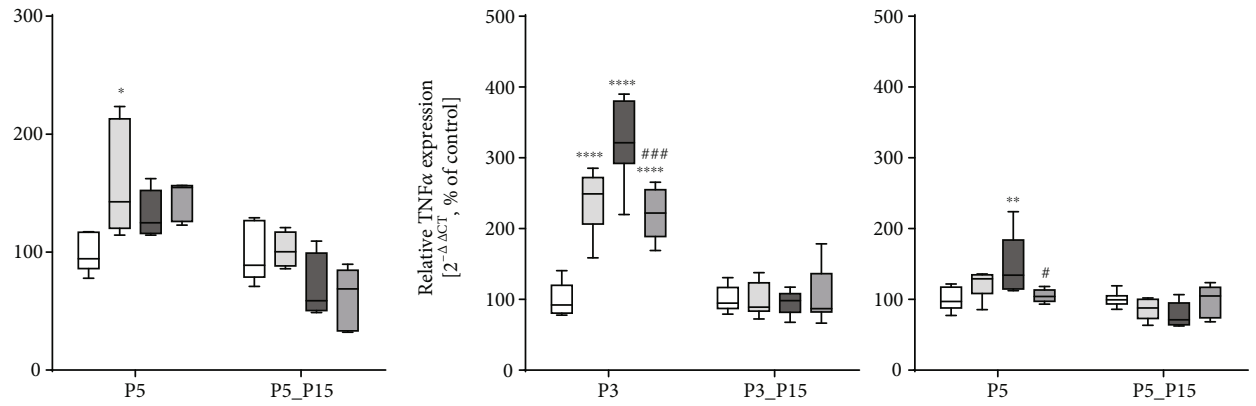

(b)
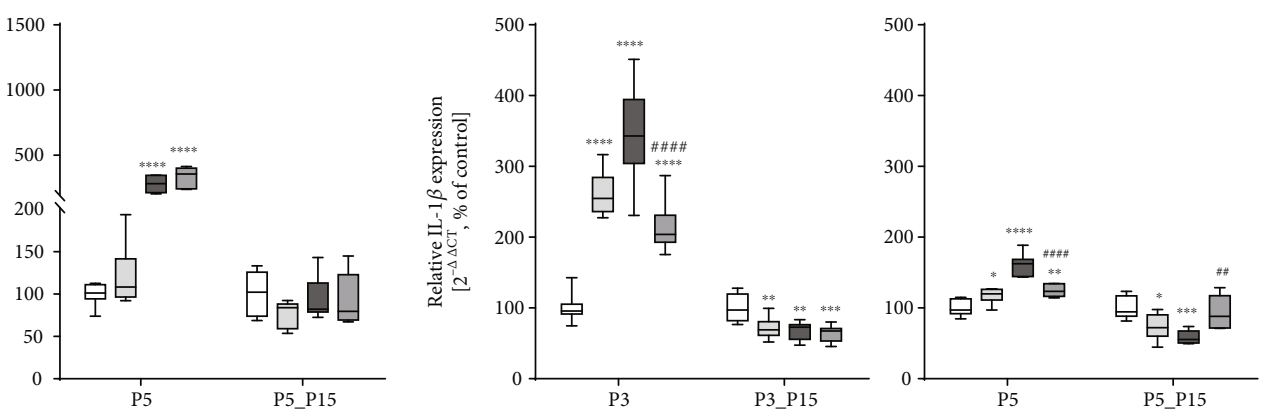

(d)
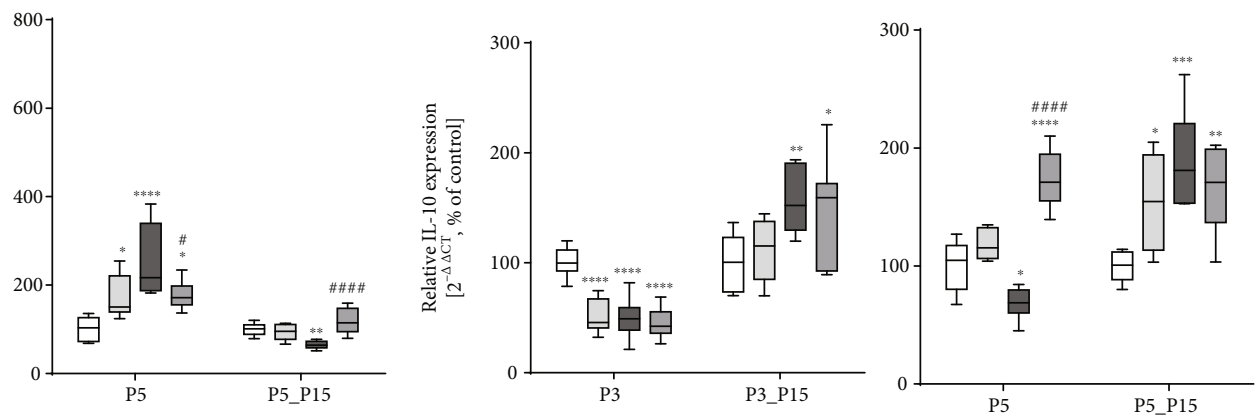

(f)
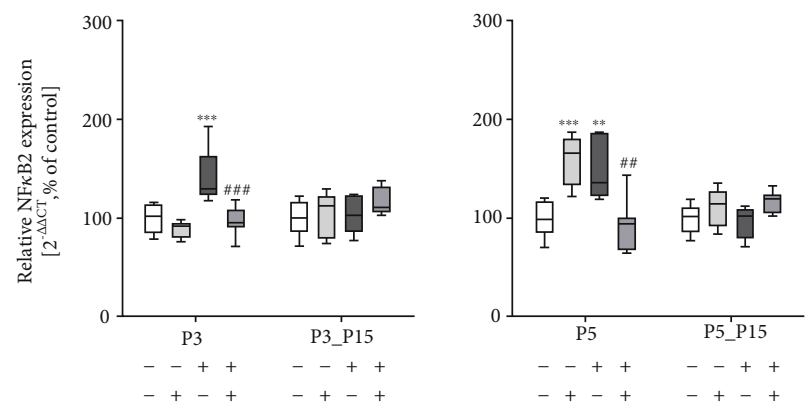

(h)

FIGURE 6: Hyperoxia exposure of newborn rat pups is characterized by modulation of cytokine response and regulation of redox-sensitive transcription factors. High oxygen led to increased proinflammatory cytokine expression of (a) TNF $\alpha$ (protein), (b) TNF $\alpha$ (RNA), (c) IL$1 \alpha$, (d) IL- $1 \beta$, and (e) IFN $\gamma$. Anti-inflammatory cytokine expression of (f) IL-10 is suppressed and redox-sensitive transcription factors (g) $\mathrm{NF} \kappa \mathrm{B} 1$ and $(\mathrm{h}) \mathrm{NF} \kappa \mathrm{B} 2$ are increased. Caffeine counteracted this. Caffeine under normoxic exposure demonstrated a massive modulation of proinflammatory cytokine expression. Quantification of lung homogenates by qPCR for 3 days' postnatal oxygen exposure (P3) and recovery (P3_P15) and 5 days' postnatal oxygen exposure (P5) and recovery (P5_P15), respectively. Data are normalized to the level of rat pups exposed to normoxia at each time point (control 100\%, white bars). The 100\% values of TNF $\alpha$ protein are 4.4 (P3), 5.6 (P3_P15), 3.5 (P5), and 7.2 (P5_P15) pg per ml, respectively. $n=7-8$ /group (qPCR); $n=5 /$ group (ELISA). ${ }^{*} p<0.05,{ }^{* *} p<0.01,{ }^{* * *} p<0.001$, and ${ }^{* * * *} p$

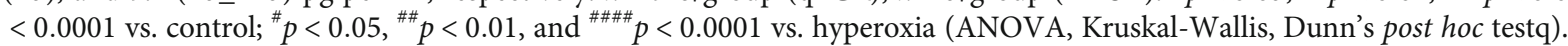


and P5 (Figure 6(c)-(e)). In hyperoxic lung-tissue, proinflammatory cytokines were no longer detected after the recovery phase $(\mathrm{P} 15)$, but rather an exhaustion of mRNA transcription was detected (IL- $1 \alpha$, IL- $1 \beta$, and IFN $\gamma$ at P3_ P15 and/or P5_P15; Figure 6(a)-(e)). Again, in normoxic animals, caffeine induced proinflammatory cytokine responses for IL- $1 \alpha$ (P3), IL-1 $\beta$ (P3 and P5), and IFN $\gamma$ (P5) mostly at the acute time points (Figure $6(\mathrm{c})-(\mathrm{e})$ ). There was a significant decrease of TNF $\alpha$, IL- $1 \alpha$, IL- $1 \beta$, and IFN $\gamma$ in the lung tissues of hyperoxic caffeine-treated rat pups (Figure 6(a)-(e)).

The expression level of IL-10 as an anti-inflammatory cytokine was significantly lower in hyperoxia-exposed rats at P3 and P5, but was significantly increased after the recovery phase. While caffeine application reduced the expression at P3, an increase of IL-10 expression was observed at P5 (Figure 6(f)).

The transcription factor $N F \kappa B$ regulates the cellular response to oxidative and inflammatory stress [53]. Hyperoxia resulted in an increased mRNA expression of the subunits $N F \kappa B 1$ and $N F \kappa B 2$ (Figure $6(\mathrm{~g})$ and (h)) acutely after oxygen exposure (P3 and P5), whereas caffeine treatment counteracted the hyperoxia-induced expression (Figure 6(g) and $(\mathrm{h}))$. Here, too, we noted an induced effect for the transcription factor under ambient air for caffeine.

3.4. Expression Pattern of Adenosine Receptor Subtypes. The regulation of the adenosine receptor subtypes has been implicated in immune modulatory responses [54]. Figure 7 shows the effects of caffeine on the mRNA expression of adenosine receptor subtypes Adora1, Adora2a, and Adora2b, revealed by qPCR. Compared to control rat pups, there was a significant decrease in the expression levels of all investigated subtypes in lung tissue of hyperoxic animals at P3 (Figure 7(a)-(c)) and of Adora2a at P5 (Figure 7(b)), whereas Adora2b expression was increased at P5 (Figure 7(c)). After recovery under normoxic conditions, high oxygen exposure for five postnatal days increased Adora1 and Adora2b expression (Figure $7(\mathrm{a})$ and (c)), while the expression of Adora2a decreased (Figure 7(b)). Caffeine under control conditions induced the expression of all investigated receptor subtypes on postnatal day 5, and this effect continued for Adora2a until P15 (Figure 7(a)-(c)).

\section{Discussion}

In the present study, we demonstrated that treatment with caffeine represses hyperoxia-induced inflammation response and apoptosis in the developing lung, coinciding with a modulation of adenosine receptor subtypes, indicating that caffeine might act as a protective drug for hyperoxia-induced developmental lung injury.

One of the major effects of high oxygen is mainly characterized by excessive activation of pulmonary inflammatory response and cell death, which are regulated at several levels; production and accumulation of excessive ROS and the inflammatory reaction triggered by hyperoxia in turn worsen the oxidative toxicity [43]. This leads to diffuse alveolar damage, death of endothelial and epithelial cell, and immune cell influx into alveolar spaces $[9,55]$. These bimodal processes of hyperoxia-induced lung damage are complex and are orchestrated by various overlapping or feedback pathways.

We demonstrate previously that caffeine diminishes oxidative stress and lung injury induced by hyperoxia [39], but little was known about effects on the secondary inflammatory response. Besides others $[56,57]$, this study confirmed that exposure to high oxygen led to a massive increase in cell death as an important pathological feature. Importantly, an increased cell death rate persists even after recovery in ambient air. Under prolonged hyperoxia until P3 and P5, an acute increase in cell death seems consistent, whereas after a recovery phase one would instead expect a normalization. The persistent cell death underlines DNA damage by oxidative stress [39] in connection with a sustained increase of alveolar macrophages and activated neutrophils at P15. Hyperoxiainduced lung injury is also the result of products of activated and recruited inflammatory cells into the lung tissue. The influx of neutrophils and monocytes into the lung is mediated by the degree of chemotactic activity such as induction of MCP-1, MIP-2, and MIF, which is highly elevated in hyperoxic lungs [52]. Proinflammatory cytokines, e.g., CINC-1 and the rat homologue of IL- 8 , are important as well in determining the levels of chemotactic activity. The reduction of oxidative stress and inhibition of immune cell infiltration with correlating downregulation of chemokines by caffeine were found to be consistent with the reduced rate of cell death. Furthermore, the determination of apoptosisassociated mediators also showed different expression levels most probably due to elevated oxidative stress. Effector caspase 3, a key enzyme in the execution of apoptosis, the caspase-independent AIF, and the catalytic subunit of glutamate cysteine ligase (GCLC) were clearly induced at the acute time points of P3 and P5. Initiation of apoptotic cell death is depending on oxygen concentration and duration of exposure $[58,59]$. Since the dysregulation of cell death was abolished by treatment with caffeine, it may serve for pharmacological modification of long-term consequences of preterm birth on lung development and tissue repair.

Proinflammatory cytokines are important mediators in hyperoxia-induced inflammatory response, which exacerbate oxidative stress injury in the lung tissue. Hyperoxia per se provokes cytokine and chemokine release as part of the inflammatory response and increased pulmonary capillary permeability, triggering the infiltration of immune cells and inhibiting alveolarization $[9,60,61]$. Tracheal aspirates from preterm neonates with BPD higher concentrations of cytokines have been detected $[62,63]$ as well as increased neutrophil filtration, which remains detectable in the airways during the first weeks of life [64]. The inflammatory response in hyperoxia-induced lung injury models of rodents is comparable to that of children affected by BPD $[45,61,65]$. As a result of oxidative damage caused by hyperoxia [39], here, we observed a drastic infiltration of immune cells as well as an overexpression of proinflammatory cytokines and chemokines in the lung tissue directly after hyperoxic exposure (P3 and P5) and following normoxic recovery (P15). These pathological alterations were largely reversed by caffeine delivery. 

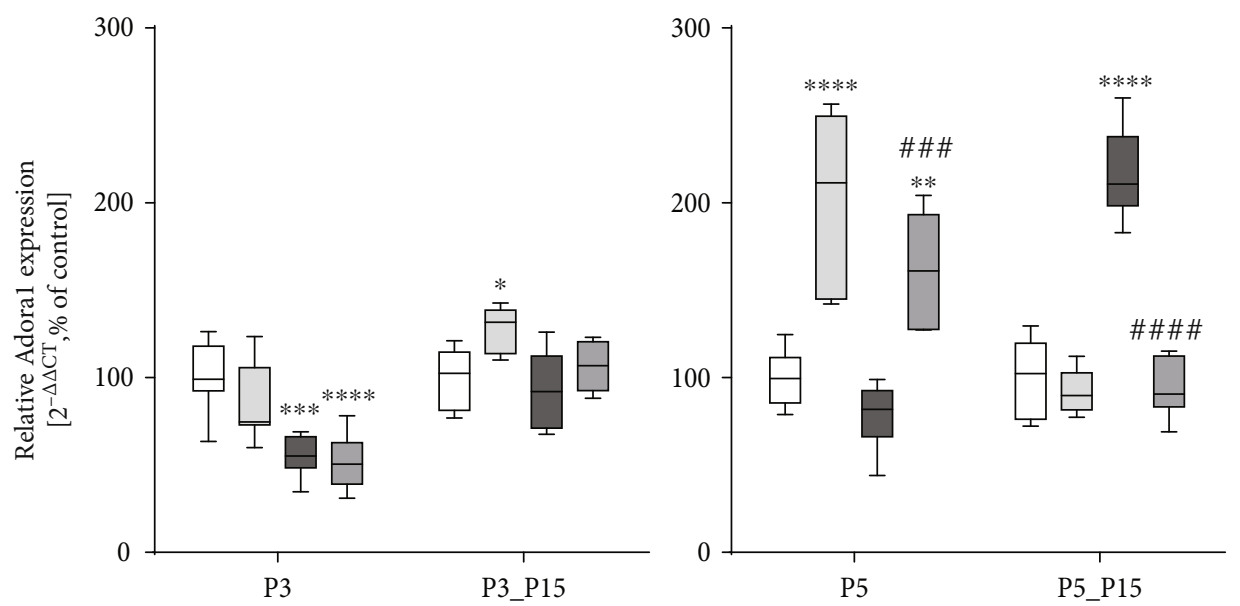

(a)
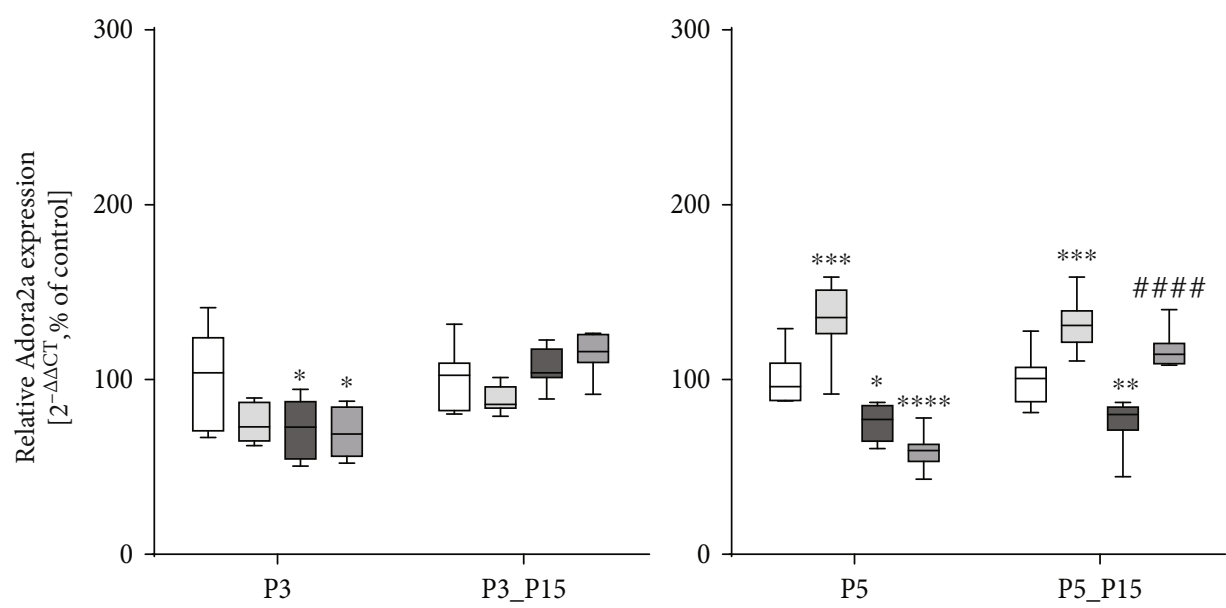

(b)
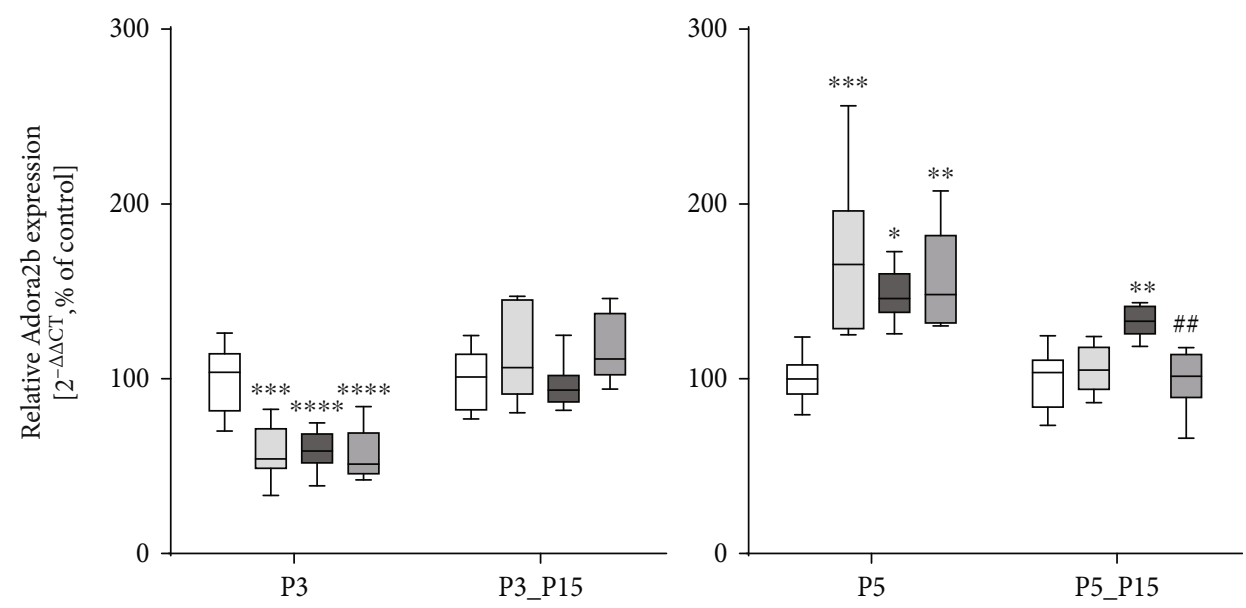

$\begin{array}{lllllllll}\text { Hyperoxia } & - & - & + & + & - & - & + & + \\ \text { Caffeine } & - & + & - & + & - & + & - & +\end{array}$

(c)

Figure 7: Hyperoxia and caffeine modulated gene expression of adenosine receptor subtypes (a) Adora1, (b) Adora2a, and (c) Adora2b. Quantification of lung homogenates was performed with qPCR for 3 days' postnatal oxygen exposure (P3) and recovery (P3_P15) and 5 days' postnatal oxygen exposure (P5) and recovery (P5_P15), respectively. Data are normalized to the level of rat pups exposed to normoxia at each time point (control $100 \%$, white bars). $n=7-8$ /group. ${ }^{*} p<0.05,{ }^{* *} p<0.01,{ }^{* * *} p<0.001$, and ${ }^{* * * *} p<0.0001$ vs. control;

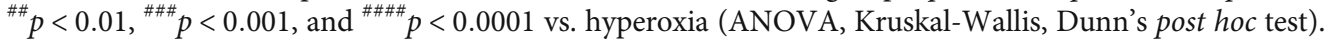


In most cases, the infiltrated cells are macrophages and neutrophils $[45,66]$. The immune cell recruitment to inflammatory sites is regulated by chemokines [58]. Chemokine expression increased dramatically after the hyperoxic insult. After recovery in room air, the number of infiltrated cells decreased in line with the chemokines but did not reach the control level. Both aspects were consistent with the increased numbers of apoptotic cells with continued elevated levels of chemoattractants, but without further increased cytokine levels. Inflammatory factors, secreted by macrophages, destroy the microvascular integrity, increase the permeability, and induce aberrant angiogenesis followed by impaired alveolarization [67]. Adverse postnatal exposure to inflammation caused sustained immune regulation followed by prolonged inflammation and lung remodeling. Oxygen exposure of mouse pups during the first four days of life within the saccular phase is sufficient to achieve impaired lung maturation by simplifying the lung structure [68]. This change in pulmonary morphology has also been demonstrated in our previous study with newborn rats, with oxidative stressdamaged lung structure beyond the onset of alveolarization [69]. Accordingly, premature infants with BPD exhibited anatomical and functional lung deficits in adolescence and adulthood [70]. In our oxygen damage model, we compared a three-day oxygen exposure (P0 to P3) associated with the saccular developmental stage (E18 to $\mathrm{P} 4$ ) to the five-day exposure (P0 to P5), up to early alveolarization (initiating P4) of the lung. The resulting immune cell infiltration as well as the inflammatory response was more strengthened when exposure occurred in the saccular phase. Studies suggest that the immature lung appears to be more susceptible to noxae in the saccular phase of development [71]. Furthermore, oxygen exposure to newborn rats during the saccular and early alveolar stages of lung development led to an immediate and persistent increase of oxidative stress [39]. Oxidative stress was associated with a persistent increase in the number of pulmonary immune cells. When monocytes migrate into the pulmonary tissue, they differentiate and become alveolar macrophages. Immunohistological staining for ED-1, a monocyte/macrophage marker, MPO for activated neutrophils, and gene expression analyses for chemoattractants for monocytes and neutrophils, respectively, showed early upregulation of MCP-1, MIP-2, and MIF, persistent until $\mathrm{P} 15$. The invading cells produce MCP-1, which acts as a chemoattractant and as an activator of monocytes [72], resulting in an enhanced monocyte recruitment. These cells also produce CINC-1, which is chemotactic for neutrophils, causing a secondary influx of neutrophils. This could explain the long-lasting presence of monocytes and neutrophils in the lung tissue after the recovery period. The fact that antineutrophilic [61] and antimacrophage [73] chemokine treatment prevented the influx of immune cells and reduced protein oxidation in newborn rats exposed to hyperoxia [39] significantly supports the essential role of the suppression of the hyperoxia-induced inflammatory response and abolishment of oxidative stress by caffeine.

The CD74 receptor mediates the binding of extracellular MIF [74]. The interaction of MIF, which is expressed by macrophages, other immune cells, and endothelial cells [75], with
CD74 leads to the activation of several signaling transduction pathways involved in the regulating inflammation and immunity $[76,77]$. In models of BPD, the interaction of MIF with CD74 expressed on the surface of alveolar macrophages resulted in MIF-induced neutrophil accumulation in the lung $[78,79]$. High MIF mRNA and protein levels within the lungs of ARDS patients are associated with acute lung injury [80]. In human ARDS patients, treatment with recombinant MIF augmented proinflammatory cytokine secretion and an anti-MIF antibody treatment attenuated proinflammatory response, which suggests the role of MIF as a mediator of pulmonary inflammation [81]. Sun et al. [82] suggest a protective response in cases of sustained hyperoxia with a significant MIF increase in the murine model by reducing lung permeability, because for one thing the loss of MIF in the MIF knock out mice was associated with increased mortality and for another the MIF overexpression in transgenic mice with better survival. Oxidative stress led to high MIF expression and consequently to the induction of cytokine transcription, MIF being a key cell cycle regulator and influencing apoptosis. In contrast, low MIF expression resulted in reduced transcription of cytokines and apoptosis-relevant genes [79]. The regulatory functions of MIF and CD74 in pathogenesis of BPD [79] are still poorly understood.

Furthermore, our results revealed that exposure to hyperoxia directly resulted in elevated levels of proinflammatory cytokine mRNA, which could be ameliorated by caffeine delivery. After recovery, the expression of proinflammatory cytokines was comparable to the control group or revealed a significant reduction in transcription. The bimodal process of hyperoxia-induced lung injury results directly from oxygen toxicity [83] and from accumulation of inflammatory cells and mediators in the pulmonary tissue [84]. The decisive mediator function of cytokines became clear in transgenic cytokine mouse models for IL-1 $\beta$ [85] and IFN $\gamma$ [86], which developed a BPD phenotype. High cytokine mRNA expressions are detected in hyperoxia-induced injury models $[87,88]$. IL-10 is considered a major anti-inflammatory cytokine [89] with pleiotropic effects in the regulation of immune response and inflammation. IL-10 is known to reduce the secretion of proinflammatory cytokines, terminate inflammatory responses, and diminish lung injury [90]. In line with this, IL-10 mRNA was decreased directly after hyperoxia, but increased after recovery. Caffeine treatment showed an arresting effect only after 5 days of oxygen, but under room air, an impressive induction of mRNA expression was found at P15. Interestingly, BPD infants demonstrated a decrease of IL-10 in tracheal aspirates [91], and hyperoxia-exposed mice showed unchanged IL-10 mRNA levels [88], whereas exogenous IL-10 treatment alleviates hyperoxia-induced acute lung injury in mice, possibly by the diminished neutrophil recruitment and subsequent generation of cytokines [92]. Furthermore, IL-10 is produced by macrophages and regulatory $\mathrm{T}$ cells (Treg) and can inhibit the release of proinflammatory cytokines by innate immune cells. Treg may be also inducible after stimulating $\mathrm{T}$ cells in a specific cytokine milieu [93]. They can suppress or downregulate immune responses through suppression of autoreactive $\mathrm{T}$ cell responses or secretion of anti-inflammatory cytokines such as IL-10 [94]. 
It is acknowledged that $\mathrm{NF} \kappa \mathrm{B}$ regulates the transcription of several genes related to the immune response to exogenous and endogenous noxae and thus plays an important role in inflammatory processes, cell survival, and developmental functions in the newborn lung [53]. Further, NFkB transcription can be activated by hyperoxia followed by amplification of inflammatory response [84], and during the saccular stage, overexpressing $\mathrm{NF} \kappa \mathrm{B}$ in the airway epithelium induces inflammation and disrupts lung development [95]. Oxidative stress rapidly activated the cellular pool of GCLC, which is important for the rate-limiting step in the formation of the antioxidant glutathione [96]. GCLC is transcriptionally controlled by $\mathrm{Nrf} 2$ and mediated by the $\mathrm{NF} \kappa \mathrm{B}$ pathway, as important regulators of ROS defense [97]. These facts suggest that redox-sensitive transcription factors, such as $\mathrm{NF} \kappa \mathrm{B}$ and Nrf2, are key mediators in oxidative stress-mediated pulmonary damage. This is consistent with our results that oxidative stress induced $\mathrm{NF} \kappa \mathrm{B}$ and $\mathrm{Nrf} 2$ [39], coinciding with GCLC activation and with the proinflammatory responses. Caffeine had an inhibitory effect on the transcription of $\mathrm{NF} \kappa \mathrm{B}$ subtypes and as well on GCLC, and thus, inflammatory cytokines and chemokines were decreased, underlining the anti-inflammatory effect of caffeine.

Caffeine reduced cell death, inflammation, and oxidative stress in the developing organism in hyperoxia-induced injury models [39, 45-47]. In line with other articles, additionally to the protective effects, undesired side effects, such as induction of chemokines and cytokines as well as modulation of the redox-sensitive transcription factor $\mathrm{NF} \kappa \mathrm{B}$, were also observed $[45,98]$. As shown in this study, caffeine affected the immune response in the sense of a significant monocyte influx without additional oxidative stress. Dayanim et al. [99] observed increased cell death due to caffeine, which we could not confirm. A potential explanation of our results might be related to dose-dependent proinflammatory and anti-inflammatory effects. Valdez et al. reported that caffeine plasma levels outside the therapeutic range of 10 to $20 \mu \mathrm{g} / \mathrm{ml}$ are associated with an increase of proinflammatory cytokines [100]. We measured at P3 and P5 plasma caffeine level between 8.8 and $11.2 \mu \mathrm{g} / \mathrm{ml}$, cited to the previous study [39], which is inside the therapeutically range [101]. However, it can be assumed that the plasma concentration was higher directly after application to P2 and P4, respectively. Hallmarks of chronic lung diseases vary; common features among oxidative stress are massive recruitment of inflammatory effector cells and the increased release of inflammatory mediators enhancing pulmonary injury. Inflammatory changes in the immature lung resulted in the disruption of pulmonary development and remodeling of the extracellular matrix [102]. Caffeine seems to be protectively preventing oxygen damage but also induced and modulated the immune response.

Caffeine is a nonspecific adenosine receptor antagonist. Adenosine per se is a signalling molecule increasingly produced upon cellular stress and an important key mediator through regulation of pulmonary inflammatory response and repair as well as alveolar development [54, 103]. Both caffeine and adenosine act through adenosine receptor subtypes (Adora1, 2a, 2b, and 3) [104], with main evidence in the lung for Adora1, 2a, and 2b. Under hyperoxic exposition, extracellular adenosine rapidly increases [105]. Elevated adenosine during acute lung injury minimized cytokine expression, immune cell infiltration, and vascular permeability, but persistent adenosine signalling in chronic lung injury increased cytokine secretion and immune cell influx in pulmonary tissue [106] as well as dysregulated tissue remodeling [54]. Caffeine blocks $\mathrm{A} 1$ and A2a adenosine receptors for natural ligand adenosine and may have caused partly the opposite effects of persistent adenosine [107]. An indication for the relevance of high adenosine concentrations in pathogenesis of lung injuries is the response enzyme to degraded adenosine is adenosine deaminase (ADA). A high adenosine level is associated with a high ADA serum level of preterm infants, which correlated with severity of disease [108]. Additionally, Adora2b is the most insensitive adenosine receptor, is expressed in low abundance, and is rarely achieved under physiological adenosine concentrations [109]. With higher adenosine sensitivity, Adora2a plays a crucial role during modulation of inflammatory response [110] and Adora1 revealed pro- and anti-inflammatory properties [111]. Our results showed a strong influence of both caffeine and oxygen on adenosine receptor transcription. While all three receptors are downregulated directly after hyperoxia, Adora2b showed an increased expression at P5. This could be interpreted as a cellular reaction to the increased adenosine secretion. Caffeine itself enhances the expression at P5 for all adenosine receptor subtypes. Caffeine with hyperoxia had little effect on adenosine receptor transcription after hyperoxia, except Adora1 at P5. Both hyperoxia and caffeine influence the transcription of the adenosine receptors. The Adora2a receptor subtype takes part in a negative feedback mechanism that limits both tissue-specific and systemic inflammatory responses [112]. Chemokines as being specifically regulated by Adora2a can modify the profile of inflammatory mediators of mononuclear cells and may limit the peak of an inflammatory response. Caffeine antagonism of Adora2a seems to modulate the production of inflammatory factor by neutrophils and reduces the inflammatory response to the oxidative stress.

Exposure to high oxygen leads to an inflammatory state within the lung, which is mediated by oxidative stress. The inflammatory response may be a result of a positive feedback cycle occurring in the production of ROS by inflammatory cells, which in turn recruits more inflammatory cells to the lung [69].

Possible working mechanisms for the effects of caffeine on hyperoxia-induced lung injury could be explained via the antioxidative caffeine metabolite 1,7 dimethyl-xanthine [113] and via the anti-inflammatory decrease of neutrophil chemokine level mediated to the antagonism of the Adora2a receptor [114]. In combination of these facts, caffeine is a potent free radical scavenger and adenosine receptor antagonist, and so caffeine reduced pulmonary tissue damage by modulation of cell death-associated mediators and of immune response. The antioxidative effect, the corresponding reduced oxidative stress response [39], and a direct effect of caffeine via the adenosine receptor subtypes probably modulated inflammation-associated pathways and 
contributed to the protective effect of caffeine in this BPD model. However, an in-depth mechanistic understanding of the crosstalk between the intracellular stress signalling pathways and inflammatory responses and any shift in the balance of inflammatory stress responses or reduction of oxidative stress may lead to a better outcome in terms of respiratory disease progression of preterm infants.

\section{Conclusions}

The level of knowledge is that oxidative stress resulted from supportive oxygen therapy in premature infants, followed by consequences such as inflammation and impairment on lung structure and function. Inflammation and oxidative stress are important contributors to the pathogenesis of BPD. No targeted therapy currently exist to prevent pulmonary inflammation and injury due oxidative stress. Caffeine is the widespread drug of choice to prevent and treat apnoea of prematurity. Caffeine therapy shortens the duration of mechanical ventilation in very and extremely premature infants and reduces the incidence of BPD. In present, clinically relevant questions are aimed at timing and duration of caffeine therapy, the targeted caffeine plasma concentration, and the consideration of prophylactic use of caffeine, which is focused on respiratory outcome in the adolescent and adulthood. To date, there is a consequent uncertainty of the long-term benefit or risk ratio of caffeine therapy.

Our study provides further evidence that caffeine exerts protective actions against hyperoxia-induced pulmonary injury, independent of oxygen exposure duration and with regard to the stages of lung development. Caffeine acts on anti-inflammatory, anti-apoptotic, and altered inflammatory responses and adenosine receptor expression. Furthermore, high oxygen concentrations also caused a sustained cell death rate beyond the recovery phase in ambient air in connection with increased chemokine levels. This might indicate an oxygen-induced long-term modulation of the immune response and thus be causal for persistent lung damage in premature infants. However, caffeine without oxidative stress unexpectedly demonstrated an overwhelming inflammatory response when applied during the saccular phase of lung development. This seems to be an impressive counterargument to preventive caffeine supplementation in extreme and very premature neonates in the absence of oxidative stress. Future research should aim at immunomodulatory effects of oxygen per se but also of caffeine, for a better understanding in the development of new therapeutic strategies. Our findings proved the relationship between oxidative stress induced by hyperoxia and subsequent inflammatory response and helped to understand the higher risk of respiratory impairments in the later life of preterm infants.

\section{Data Availability}

The data used to support the findings of this study are available from the corresponding author upon request.

\section{Ethical Approval}

All animal procedures were approved by the local animal welfare authorities (LAGeSo, approval number G-0088/16) and followed institutional guidelines.

\section{Conflicts of Interest}

The authors declare that there is no conflict of interest.

\section{Authors' Contributions}

SE conceived the ideas, designed and executed the experiments, and wrote the first draft of the manuscript and approved the final draft; SE and ES performed the animal studies; ES performed and analyzed ELISA the experiments; ES performed immunostaining; IB, TS, and CB revised the manuscript and contributed to the critical discussion. All authors read and approved the final manuscript.

\section{Acknowledgments}

This research was supported from the employer, Department of Neonatology, Charité-Universitätsmedizin Berlin, Germany, and received no specific grant from any funding agency in the public, commercial, or not-for-profit sectors.

\section{References}

[1] I. Panfoli, G. Candiano, M. Malova et al., "Oxidative stress as a primary risk factor for brain damage in preterm newborns," Frontiers in Pediatrics, vol. 6, p. 369, 2018.

[2] A. Castillo, A. Sola, H. Baquero et al., "Pulse oxygen saturation levels and arterial oxygen tension values in newborns receiving oxygen therapy in the neonatal intensive care unit: is $85 \%$ to $93 \%$ an acceptable range?," Pediatrics, vol. 121, no. 5, pp. 882-889, 2008.

[3] R. Negi, D. Pande, A. Kumar, R. S. Khanna, and H. D. Khanna, "Evaluation of biomarkers of oxidative stress and antioxidant capacity in the cord blood of preterm low birth weight neonates," The Journal of Maternal-Fetal \& Neonatal Medicine, vol. 25, no. 8, pp. 1338-1341, 2012.

[4] S. Perrone, C. Bracciali, N. di Virgilio, and G. Buonocore, "Oxygen use in neonatal care: a two-edged sword," Frontiers in Pediatrics, vol. 4, pp. 143-143, 2017.

[5] J. R. C. Parkinson, M. J. Hyde, C. Gale, S. Santhakumaran, and N. Modi, "Preterm birth and the metabolic syndrome in adult life: a systematic review and meta-analysis," Pediatrics, vol. 131, no. 4, pp. e1240-e1263, 2013.

[6] S. Li, M. Zhang, H. Tian, Z. Liu, X. Yin, and B. Xi, "Preterm birth and risk of type 1 and type 2 diabetes: systematic review and meta-analysis," Obesity Reviews, vol. 15, no. 10, pp. 804811, 2014.

[7] P. Um-Bergström, J. Hallberg, P. Thunqvist et al., "Lung function development after preterm birth in relation to severity of bronchopulmonary dysplasia," BMC Pulmonary Medicine, vol. 17, no. 1, p. 97, 2017.

[8] R. E. Morty, "Recent advances in the pathogenesis of BPD," Seminars in Perinatology, vol. 42, no. 7, pp. 404-412, 2018. 
[9] V. Bhandari, "Hyperoxia-derived lung damage in preterm infants," Seminars in Fetal \& Neonatal Medicine, vol. 15, no. 4, pp. 223-229, 2010.

[10] J. Wang and W. Dong, "Oxidative stress and bronchopulmonary dysplasia,” Gene, vol. 678, pp. 177-183, 2018.

[11] L. W. Doyle, J. L. Cheong, R. A. Ehrenkranz, and H. L. Halliday, "Early (<8 days) systemic postnatal corticosteroids for prevention of bronchopulmonary dysplasia in preterm infants," Cochrane Database of Systematic Reviews, vol. 10, no. 10, article CD001146, 2017.

[12] L. W. Doyle, J. L. Cheong, R. A. Ehrenkranz, and H. L. Halliday, "Late ( $>7$ days) systemic postnatal corticosteroids for prevention of bronchopulmonary dysplasia in preterm infants," Cochrane Database of Systematic Reviews, vol. 10, no. 10, article CD001145, 2018.

[13] T. Isayama, H. Iwami, S. McDonald, and J. Beyene, "Association of noninvasive ventilation strategies with mortality and bronchopulmonary dysplasia among preterm infants: a systematic review and meta-analysis," JAMA, vol. 316, no. 6, pp. 611-624, 2016.

[14] D. G. Sweet, V. Carnielli, G. Greisen et al., "European Consensus Guidelines on the Management of Respiratory Distress Syndrome - 2019 Update," Neonatology, vol. 115, no. 4, pp. 432-450, 2019.

[15] O. D. Saugstad, "Oxygenation of the immature infant: a commentary and recommendations for oxygen saturation targets and alarm limits," Neonatology, vol. 114, no. 1, pp. 69-75, 2018.

[16] C. Poggi and C. Dani, "Antioxidant strategies and respiratory disease of the preterm newborn: an update," Oxidative Medicine and Cellular Longevity, vol. 2014, Article ID 721043, 10 pages, 2014.

[17] B. A. Darlow, P. J. Graham, and M. X. Rojas-Reyes, "Vitamin A supplementation to prevent mortality and short- and longterm morbidity in very low birth weight infants," Cochrane Database of Systematic Reviews, vol. 2016, no. 8, article CD000501, 2016.

[18] B. D. Garg, A. Bansal, and N. S. Kabra, "Role of vitamin A supplementation in prevention of bronchopulmonary dysplasia in extremely low birth weight neonates: a systematic review of randomized trials," The Journal of MaternalFetal \& Neonatal Medicine, vol. 32, no. 15, pp. 26082615, 2019.

[19] B. Schmidt, R. S. Roberts, P. Davis et al., "Caffeine therapy for apnea of prematurity," New England Journal of Medicine, vol. 354, no. 20, pp. 2112-2121, 2006.

[20] D. J. Henderson-Smart and A. G. de Paoli, "Methylxanthine treatment for apnoea in preterm infants," Cochrane Database of Systematic Reviews, vol. 2010, no. 12, article CD000140, 2010.

[21] M. Sanchez-Solis, P. W. Garcia-Marcos, J. Aguera-Arenas, P. Mondejar-Lopez, and L. Garcia-Marcos, "Impact of early caffeine therapy in preterm newborns on infant lung function," Pediatric Pulmonology, vol. 55, no. 1, pp. 102-107, 2020.

[22] M. A. Pakvasa, V. Saroha, and R. M. Patel, "Optimizing caffeine use and risk of bronchopulmonary dysplasia in preterm infants: a systematic review, meta-analysis, and application of grading of recommendations assessment, development, and evaluation methodology," Clinics in Perinatology, vol. 45, no. 2, pp. 273-291, 2018.
[23] K. Belkhatir, S. Zivanovic, H. Lumgair et al., "Variations in preterm stabilisation practices and caffeine therapy between two European tertiary level neonatal units," Acta Paediatrica, vol. 109, no. 3, pp. 488-493, 2020.

[24] D. J. Henderson-Smart and A. G. de Paoli, "Prophylactic methylxanthine for prevention of apnoea in preterm infants," Cochrane Database of Systematic Reviews, vol. 2010, no. 12, article CD000432, 2010.

[25] K. P. Kua and S. W. H. Lee, "Systematic review and metaanalysis of clinical outcomes of early caffeine therapy in preterm neonates," British Journal of Clinical Pharmacology, vol. 83, no. 1, pp. 180-191, 2017.

[26] L. Moschino, S. Zivanovic, C. Hartley, D. Trevisanuto, E. Baraldi, and C. C. Roehr, "Caffeine in preterm infants: where are we in 2020?," ERJ Open Research, vol. 6, no. 1, pp. 00330-02019, 2020.

[27] C. D. Baker and C. M. Alvira, "Disrupted lung development and bronchopulmonary dysplasia: opportunities for lung repair and regeneration," Current Opinion in Pediatrics, vol. 26, no. 3, pp. 306-314, 2014.

[28] M. Laube, E. Amann, U. Uhlig et al., "Inflammatory mediators in tracheal aspirates of preterm infants participating in a randomized trial of inhaled nitric oxide," PLoS One, vol. 12, no. 1, article e0169352, 2017.

[29] D. Zhou, F. Shi, Y. Xiong, M. Zhou, H. Wan, and H. Liu, "Increased serum Th2 chemokine levels are associated with bronchopulmonary dysplasia in premature infants," European Journal of Pediatrics, vol. 178, no. 1, pp. 81-87, 2019.

[30] R. C. Savani, "Modulators of inflammation in bronchopulmonary dysplasia," Seminars in Perinatology, vol. 42, no. 7, pp. 459-470, 2018.

[31] M. May, P. Ströbel, T. Preisshofen, S. Seidenspinner, A. Marx, and C. P. Speer, "Apoptosis and proliferation in lungs of ventilated and oxygen-treated preterm infants," European Respiratory Journal, vol. 23, no. 1, pp. 113-121, 2014.

[32] B. Hargitai, V. Szabó, J. Hajdú et al., "Apoptosis in various organs of preterm infants: histopathologic study of lung, kidney, liver, and brain of ventilated infants," Pediatric Research, vol. 50, no. 1, pp. 110-114, 2001.

[33] C. Nardiello, I. Mižíková, and R. E. Morty, "Looking ahead: where to next for animal models of bronchopulmonary dysplasia?," Cell and Tissue Research, vol. 367, no. 3, pp. 457$468,2017$.

[34] P. H. Burri, "Structural aspects of postnatal lung development - alveolar formation and growth," Biology of the Neonate, vol. 89, no. 4, pp. 313-322, 2006.

[35] Z. Kassim, A. Greenough, and G. F. Rafferty, "Effect of caffeine on respiratory muscle strength and lung function in prematurely born, ventilated infants," European Journal of Pediatrics, vol. 168, no. 12, article 1491, 2009.

[36] D. M. G. Silva, C. Nardiello, A. Pozarska, and R. E. Morty, "Recent advances in the mechanisms of lung alveolarization and the pathogenesis of bronchopulmonary dysplasia," American Journal of Physiology-Lung Cellular and Molecular Physiology, vol. 309, no. 11, pp. L1239-L1272, 2015.

[37] J. C. Schittny, "Development of the lung," Cell and Tissue Research, vol. 367, no. 3, pp. 427-444, 2017.

[38] R. L. Auten and J. M. Davis, "Oxygen toxicity and reactive oxygen species: the devil is in the details," Pediatric Research, vol. 66, no. 2, pp. 121-127, 2009. 
[39] S. Endesfelder, E. Strauß, T. Scheuer, T. Schmitz, and C. Bührer, "Antioxidative effects of caffeine in a hyperoxiabased rat model of bronchopulmonary dysplasia," Respiratory Research, vol. 20, no. 1, p. 88, 2019.

[40] M. C. Walsh, S. Szefler, J. Davis et al., "Summary proceedings from the bronchopulmonary dysplasia group," Pediatrics, vol. 117, Supplement 1, pp. S52-S56, 2006.

[41] A. C. Nagato, F. S. Bezerra, M. Lanzetti et al., "Time course of inflammation, oxidative stress and tissue damage induced by hyperoxia in mouse lungs," International Journal of Experimental Pathology, vol. 93, no. 4, pp. 269-278, 2012.

[42] A. Nagato, F. L. Silva, A. R. Silva et al., "Hyperoxia-induced lung injury is dose dependent in Wistar rats," Experimental Lung Research, vol. 35, no. 8, pp. 713-728, 2009.

[43] A. Pagano and C. Barazzone-Argiroffo, "Alveolar cell death in hyperoxia-induced lung injury," Annals of the New York Academy of Sciences, vol. 1010, no. 1, pp. 405-416, 2003.

[44] B. B. Fredholm, K. Battig, J. Holmen, A. Nehlig, and E. E. Zvartau, "Actions of caffeine in the brain with special reference to factors that contribute to its widespread use," Pharmacological Reviews, vol. 51, no. 1, pp. 83-133, 1999.

[45] U. Weichelt, R. Cay, T. Schmitz et al., "Prevention of hyperoxia-mediated pulmonary inflammation in neonatal rats by caffeine," European Respiratory Journal, vol. 41, no. 4, pp. 966-973, 2013.

[46] T. Nagatomo, J. Jiménez, J. Richter et al., "Caffeine prevents hyperoxia-induced functional and structural lung damage in preterm rabbits," Neonatology, vol. 109, no. 4, pp. 274281, 2016.

[47] R. J. Teng, X. Jing, T. Michalkiewicz, A. J. Afolayan, T. J. Wu, and G. G. Konduri, "Attenuation of endoplasmic reticulum stress by caffeine ameliorates hyperoxia-induced lung injury," American Journal of Physiology. Lung Cellular and Molecular Physiology, vol. 312, no. 5, pp. L586-L598, 2017.

[48] F. Faul, E. Erdfelder, A. G. Lang, and A. Buchner, "G * Power 3: a flexible statistical power analysis program for the social, behavioral, and biomedical sciences," Behavior Research Methods, vol. 39, no. 2, pp. 175-191, 2007.

[49] K. J. Livak and T. D. Schmittgen, "Analysis of Relative Gene Expression Data Using Real-Time Quantitative PCR and the $2^{-\triangle \Delta C T}$ Method," Methods, vol. 25, no. 4, pp. 402-408, 2001.

[50] S. Endesfelder, U. Weichelt, C. Schiller, M. Sifringer, I. Bendix, and C. Buhrer, "Caffeine protects against anticonvulsant-induced neurotoxicity in the developing rat brain," Neurotoxicity Research, vol. 32, no. 3, pp. 460-472, 2017.

[51] S. Endesfelder, U. Weichelt, E. Strauß et al., "Neuroprotection by caffeine in hyperoxia-induced neonatal brain injury," International Journal of Molecular Sciences, vol. 18, no. 1, p. 187, 2017.

[52] M. Bhatia, R. L. Zemans, and S. Jeyaseelan, "Role of chemokines in the pathogenesis of acute lung injury," American Journal of Respiratory Cell and Molecular Biology, vol. 46, no. 5, pp. 566-572, 2012.

[53] S. McKenna, K. A. Michaelis, F. Agboke et al., "Sustained hyperoxia-induced NF- $\kappa$ B activation improves survival and preserves lung development in neonatal mice," American Journal of Physiology. Lung Cellular and Molecular Physiology, vol. 306, no. 12, pp. L1078-L1089, 2014.
[54] H. Karmouty-Quintana, Y. Xia, and M. R. Blackburn, "Adenosine signaling during acute and chronic disease states," Journal of Molecular Medicine, vol. 91, no. 2, pp. 173-181, 2013.

[55] I. Shimada, A. Kubota, M. Katoh, and F. Suzuki, "Hyperoxia causes diffuse alveolar damage through mechanisms involving upregulation of $c-M y c / B a x$ and enhanced production of reactive oxygen species," Respiratory Investigation, vol. 54, no. 1, pp. 59-68, 2016.

[56] X. Zhu, X. Lei, J. Wang, and W. Dong, "Protective effects of resveratrol on hyperoxia-induced lung injury in neonatal rats by alleviating apoptosis and ROS production," The Journal of Maternal-Fetal \& Neonatal Medicine, pp. 1-9, 2019.

[57] Q. Zhang, D. Wu, Y. Yang, T. Liu, and H. Liu, "Dexmedetomidine alleviates hyperoxia-induced acute lung injury via inhibiting NLRP3 inflammasome activation," Cellular Physiology and Biochemistry, vol. 42, no. 5, pp. 1907-1919, 2017.

[58] V. Bhandari and J. A. Elias, "Cytokines in tolerance to hyperoxia-induced injury in the developing and adult lung," Free Radical Biology and Medicine, vol. 41, no. 1, pp. 4-18, 2006

[59] T. E. Zaher, E. J. Miller, D. M. P. Morrow, M. Javdan, and L. L. Mantell, "Hyperoxia-induced signal transduction pathways in pulmonary epithelial cells," Free Radical Biology and Medicine, vol. 42, no. 7, pp. 897-908, 2007.

[60] W. Thomas and C. P. Speer, "Chorioamnionitis is essential in the evolution of bronchopulmonary dysplasia - The case in favour," Paediatric Respiratory Reviews, vol. 15, no. 1, pp. 49-52, 2014.

[61] R. L. Auten Jr., S. N. Mason, D. T. Tanaka, K. Welty-Wolf, and M. H. Whorton, "Anti-neutrophil chemokine preserves alveolar development in hyperoxia-exposed newborn rats," American Journal of Physiology. Lung Cellular and Molecular Physiology, vol. 281, no. 2, pp. L336-L344, 2001.

[62] C. Yilmaz, N. Koksal, H. Ozkan, B. A. Dorum, and O. Bagci, "Low serum IGF-1 and increased cytokine levels in tracheal aspirate samples are associated with bronchopulmonary dysplasia," The Turkish Journal of Pediatrics, vol. 59, no. 2, pp. 122-129, 2017.

[63] U. K. Munshi, J. O. Niu, M. M. Siddiq, and L. A. Parton, "Elevation of interleukin- 8 and interleukin- 6 precedes the influx of neutrophils in tracheal aspirates from preterm infants who develop bronchopulmonary dysplasia," Pediatric Pulmonology, vol. 24, no. 5, pp. 331-336, 1997.

[64] R. Hsiao and S. A. Omar, "Outcome of extremely low birth weight infants with leukemoid reaction," Pediatrics, vol. 116, no. 1, pp. e43-e51, 2005.

[65] L. Zhang, S. Zhao, L. Yuan et al., "Knockdown of placental growth factor (PLGF) mitigates hyperoxia-induced acute lung injury in neonatal rats: Suppressive effects on $\mathrm{NF} \kappa \mathrm{B}$ signaling pathway," International Immunopharmacology, vol. 38, pp. 167-174, 2016.

[66] L. Galam, A. Rajan, A. Failla, R. Soundararajan, R. F. Lockey, and N. Kolliputi, "Deletion of P2X7 attenuates hyperoxiainduced acute lung injury via inflammasome suppression," American Journal of Physiology. Lung Cellular and Molecular Physiology, vol. 310, no. 6, pp. L572-L581, 2016.

[67] T. V. Kalymbetova, B. Selvakumar, J. A. Rodríguez-Castillo et al., "Resident alveolar macrophages are master regulators of arrested alveolarization in experimental bronchopulmonary dysplasia," The Journal of Pathology, vol. 245, no. 2, pp. 153-159, 2018. 
[68] M. A. O'Reilly, S. H. Marr, M. Yee, S. A. McGrath-Morrow, and B. P. Lawrence, "Neonatal hyperoxia enhances the inflammatory response in adult mice infected with influenza A virus," American Journal of Respiratory and Critical Care Medicine, vol. 177, no. 10, pp. 1103-1110, 2008.

[69] D. P. Rosanna and C. Salvatore, "Reactive oxygen species, inflammation, and lung diseases," Current Pharmaceutical Design, vol. 18, no. 26, pp. 3889-3900, 2012.

[70] A. Bhandari and S. McGrath-Morrow, "Long-term pulmonary outcomes of patients with bronchopulmonary dysplasia," Seminars in Perinatology, vol. 37, no. 2, pp. 132-137, 2013.

[71] D. E. Surate Solaligue, J. A. Rodriguez-Castillo, K. Ahlbrecht, and R. E. Morty, "Recent advances in our understanding of the mechanisms of late lung development and bronchopulmonary dysplasia," American Journal of Physiology. Lung Cellular and Molecular Physiology, vol. 313, no. 6, pp. L1101-L1153, 2017.

[72] B. J. Rollins, A. Walz, and M. Baggiolini, "Recombinant human MCP-1/JE induces chemotaxis, calcium flux, and the respiratory burst in human monocytes," Blood, vol. 78, no. 4, pp. 1112-1116, 1991.

[73] M. A. Vozzelli, S. N. Mason, M. H. Whorton, and R. L. Auten Jr., "Antimacrophage chemokine treatment prevents neutrophil and macrophage influx in hyperoxia-exposed newborn rat lung," American Journal of Physiology. Lung Cellular and Molecular Physiology, vol. 286, no. 3, pp. L488-L493, 2004.

[74] L. Leng, C. N. Metz, Y. Fang et al., "MIF signal transduction initiated by binding to CD74," Journal of Experimental Medicine, vol. 197, no. 11, pp. 1467-1476, 2003.

[75] T. Calandra and T. Roger, "Macrophage migration inhibitory factor: a regulator of innate immunity," Nature Reviews Immunology, vol. 3, no. 10, pp. 791-800, 2003.

[76] G. Wu, Y. Sun, K.'a. Wang et al., "Relationship between elevated soluble CD74 and severity of experimental and clinical ALI/ARDS," Scientific Reports, vol. 6, no. 1, article 30067, 2016.

[77] K. Takahashi, K. Koga, H. M. Linge et al., "Macrophage CD74 contributes to MIF-induced pulmonary inflammation," Respiratory Research, vol. 10, no. 1, 2009.

[78] R. L. Auten, S. N. Mason, K. M. Auten, and M. Brahmajothi, "Hyperoxia impairs postnatal alveolar epithelial development via NADPH oxidase in newborn mice," American Journal of Physiology. Lung Cellular and Molecular Physiology, vol. 297, no. 1, pp. L134-L142, 2009.

[79] M. Sauler, R. Bucala, and P. J. Lee, "Role of macrophage migration inhibitory factor in age-related lung disease," American Journal of Physiology. Lung Cellular and Molecular Physiology, vol. 309, no. 1, pp. L1-L10, 2015.

[80] L. Gao, C. Flores, S. Fan-Ma et al., "Macrophage migration inhibitory factor in acute lung injury: expression, biomarker, and associations," Translational Research, vol. 150, no. 1, pp. 18-29, 2007.

[81] S. C. Donnelly, C. Haslett, P. T. Reid et al., "Regulatory role for macrophage migration inhibitory factor in acute respiratory distress syndrome," Nature Medicine, vol. 3, no. 3, pp. 320-323, 1997.

[82] H. Sun, R. Choo-Wing, A. Sureshbabu et al., "A critical regulatory role for macrophage migration inhibitory factor in hyperoxia-induced injury in the developing murine lung," PLoS One, vol. 8, no. 4, article e60560, 2013.
[83] C. W. Chow, M. T. Herrera Abreu, T. Suzuki, and G. P. Downey, "Oxidative stress and acute lung injury," American Journal of Respiratory Cell and Molecular Biology, vol. 29, no. 4, pp. 427-431, 2003.

[84] A. Gore, M. Muralidhar, M. G. Espey, K. Degenhardt, and L. L. Mantell, "Hyperoxia sensing: from molecular mechanisms to significance in disease," Journal of Immunotoxicology, vol. 7, no. 4, pp. 239-254, 2010.

[85] E. Backstrom, A. Hogmalm, U. Lappalainen, and K. Bry, "Developmental stage is a major determinant of lung injury in a murine model of bronchopulmonary dysplasia," Pediatric Research, vol. 69, no. 4, pp. 312-318, 2011.

[86] R. Choo-Wing, M. A. Syed, A. Harijith et al., "Hyperoxia and interferon- $\gamma$-induced injury in developing lungs occur via cyclooxygenase- 2 and the endoplasmic reticulum stressdependent pathway," American Journal of Respiratory Cell and Molecular Biology, vol. 48, no. 6, pp. 749-757, 2013.

[87] B. B. Warner, L. A. Stuart, R. A. Papes, and J. R. Wispe, "Functional and pathological effects of prolonged hyperoxia in neonatal mice," American Journal of Physiology. Lung Cellular and Molecular Physiology, vol. 275, no. 1, pp. L110L117, 1998.

[88] C. J. Johnston, T. W. Wright, C. K. Reed, and J. N. Finkelstein, "Comparison of adult and newborn pulmonary cytokine mRNA expression after hyperoxia," Experimental Lung Research, vol. 23, no. 6, pp. 537-552, 1997.

[89] M. Saraiva and A. O'Garra, "The regulation of IL-10 production by immune cells," Nature Reviews Immunology, vol. 10, no. 3, pp. 170-181, 2010.

[90] E. Manning, S. Pham, S. Li et al., "Interleukin-10 delivery via mesenchymal stem cells: a novel gene therapy approach to prevent lung ischemia-reperfusion injury," Human Gene Therapy, vol. 21, no. 6, pp. 713-727, 2010.

[91] A. Thompson and V. Bhandari, "Pulmonary biomarkers of bronchopulmonary dysplasia," Biomarker Insights, vol. 3, article BMI.S834, 2008.

[92] H. D. Li, Q. X. Zhang, Z. Mao, X. J. Xu, N. Y. Li, and $\mathrm{H}$. Zhang, "Exogenous interleukin-10 attenuates hyperoxiainduced acute lung injury in mice," Experimental Physiology, vol. 100, no. 3, pp. 331-340, 2015.

[93] A. Ohta, "Oxygen-dependent regulation of immune checkpoint mechanisms," International Immunology, vol. 30, no. 8, pp. 335-343, 2018.

[94] J. Lopez-Pastrana, X. Sha, A. Virtue et al., "Regulatory T cells and atherosclerosis," Journal of Clinical \& Experimental Cardiology, vol. 1, Supplement 12, 2013.

[95] J. T. Benjamin, R. van der Meer, A. M. Im et al., "Epithelialderived inflammation disrupts elastin assembly and alters saccular stage lung development," The American Journal of Pathology, vol. 186, no. 7, pp. 1786-1800, 2016.

[96] C. M. Krejsa, C. C. Franklin, C. C. White, J. A. Ledbetter, G. L. Schieven, and T. J. Kavanagh, "Rapid activation of glutamate cysteine ligase following oxidative stress," Journal of Biological Chemistry, vol. 285, no. 21, pp. 1611616124, 2010.

[97] H. Yang, N. Magilnick, C. Lee et al., "Nrf1 and Nrf2 regulate rat glutamate-cysteine ligase catalytic subunit transcription indirectly via NF- $\kappa \mathrm{B}$ and AP-1," Molecular and Cellular Biology, vol. 25, no. 14, pp. 5933-5946, 2015.

[98] S. Endesfelder, H. Makki, C. von Haefen, C. D. Spies, C. Buhrer, and M. Sifringer, "Neuroprotective effects of 
dexmedetomidine against hyperoxia-induced injury in the developing rat brain," PLoS One, vol. 12, no. 2, article e0171498, 2017.

[99] S. Dayanim, B. Lopez, T. M. Maisonet, S. Grewal, and V. A. Londhe, "Caffeine induces alveolar apoptosis in the hyperoxia-exposed developing mouse lung," Pediatric Research, vol. 75, no. 3, pp. 395-402, 2014.

[100] R. Chavez Valdez, R. Ahlawat, M. Wills-Karp, A. Nathan, T. Ezell, and E. B. Gauda, "Correlation between serum caffeine levels and changes in cytokine profile in a cohort of preterm infants," The Journal of Pediatrics, vol. 158, no. 1, pp. 57-64.e1, 2011.

[101] H. Abdel-Hady, N. Nasef, and I. N. Abd Elazeez Shabaan, "Caffeine therapy in preterm infants," Journal of Korean Society of Health-System Pharmacists, vol. 32, no. 2, pp. 140-146, 2015.

[102] Y. Zhou, J. C. Horowitz, A. Naba et al., "Extracellular matrix in lung development, homeostasis and disease," Matrix Biology, vol. 73, pp. 77-104, 2018.

[103] S. K. Banerjee, H. W. J. Young, A. Barczak, D. J. Erle, and M. R. Blackburn, "Abnormal alveolar development associated with elevated adenine nucleosides," American Journal of Respiratory Cell and Molecular Biology, vol. 30, no. 1, pp. 38-50, 2004.

[104] B. B. Fredholm, “Adenosine receptors as drug targets," Experimental Cell Research, vol. 316, no. 8, pp. 1284-1288, 2010.

[105] J. Davies, H. Karmouty-Quintana, T. T. le et al., "Adenosine promotes vascular barrier function in hyperoxic lung injury," Physiological Reports, vol. 2, no. 9, article e12155, 2014.

[106] H. Li, H. Karmouty-Quintana, N. Y. Chen et al., "Loss of CD73-mediated extracellular adenosine production exacerbates inflammation and abnormal alveolar development in newborn mice exposed to prolonged hyperoxia," Pediatric Research, vol. 82, no. 6, pp. 1039-1047, 2017.

[107] R. Chavez-Valdez, M. Wills-Karp, R. Ahlawat, E. A. Cristofalo, A. Nathan, and E. B. Gauda, "Caffeine Modulates TNF- $\alpha$ Production by Cord Blood Monocytes: The Role of Adenosine Receptors," Pediatric Research, vol. 65, no. 2, pp. 203-208, 2009.

[108] F. E. Canpolat, M. Yurdakok, A. Korkmaz, S. Yigit, and G. Tekinalp, "Adenosine deaminase levels in premature infants with respiratory distress syndrome and bronchopulmonary dysplasia," The Journal of Maternal-Fetal \& Neonatal Medicine, vol. 24, no. 5, pp. 703-707, 2011.

[109] U. Schingnitz, K. Hartmann, C. F. MacManus et al., "Signaling through the $\mathrm{A} 2 \mathrm{~B}$ adenosine receptor dampens endotoxininduced acute lung injury," Journal of Immunology, vol. 184, no. 9, pp. 5271-5279, 2010.

[110] B. B. Fredholm, A. P. IJzerman, K. A. Jacobson, J. Linden, and C. E. Müller, "International Union of Basic and Clinical Pharmacology. LXXXI. Nomenclature and classification of adenosine receptors-an update," Pharmacological Reviews, vol. 63, no. 1, pp. 1-34, 2011.

[111] J.-F. Chen, H. K. Eltzschig, and B. B. Fredholm, "Adenosine receptors as drug targets - what are the challenges?," Nature Reviews Drug Discovery, vol. 12, no. 4, pp. 265286, 2013.

[112] A. Ohta and M. Sitkovsky, "Role of G-protein-coupled adenosine receptors in downregulation of inflammation and protection from tissue damage," Nature, vol. 414, no. 6866, pp. 916-920, 2001.
[113] S. A. J. ter Horst, G. T. M. Wagenaar, E. de Boer et al., "Pentoxifylline reduces fibrin deposition and prolongs survival in neonatal hyperoxic lung injury," Journal of Applied Physiology, vol. 97, no. 5, pp. 2014-2019, 2004.

[114] S. R. McColl, M. St-Onge, A. A. Dussault et al., "Immunomodulatory impact of the $\mathrm{A} 2 \mathrm{~A}$ adenosine receptor on the profile of chemokines produced by neutrophils," The FASEB Journal, vol. 20, no. 1, pp. 187-189, 2006. 